International Journal of Social Science and Economic Research

ISSN: 2455-8834

Volume:06, Issue:06 "June 2021"

\title{
ROLE OF SOCIAL MEDIA IN PERSPECTIVE OF MANAGEMENT STUDIES
}

\author{
Manan Sehgal \\ Delhi Public School, Dwarka \\ DOI: 10.46609/IJSSER.2021.v06i06.016 URL: https://doi.org/10.46609/IJSSER.2021.v06i06.016
}

\begin{abstract}
This paper first deals with the definitions of social media management, and analyses how in contemporary times, it is essential and effective in the perspective of business management. It then analyses the depths of social media and how it is contributing to management. A review of existing literature from 30 research papers is then given. Further, a survey conducted on the same topic is discussed and analyzed in detail revealing details about the point of view of employees and how they see the use of social media in their company. The paper explores the potent ways in which social media is contributing to the corporate world. The conclusion looks at the importance of social media, it's challenges, how it will be an essential part of the future and summarises the survey results.
\end{abstract}

\section{INTRODUCTION}

As mentioned, the process of creating, posting, promoting, and managing content through social media platforms such as Facebook, Instagram, Twitter, LinkedIn, YouTube, and Pinterest is social media management. Management of social media goes beyond just adding updates to the social media accounts of the company. It also involves communicating with your audience and searching for new possibilities to improve exposure and scope. For several company leaders, the idea of Social Media (SM) was at the top of the agenda. Decision makers, as well as experts, aim to find ways in which businesses can use apps such as Wikipedia, YouTube, Facebook, Twitter, etc. profitably. Consumers have historically used the Internet to simply invest their content: they read it, watched it, and used it to purchase goods and services. This illustrates the phenomenon of social media, which can now dramatically affect the credibility, revenue, and even survival of a business. However, many managers avoid or disregard this type of media because they do not understand what it is, the different forms it can take, and how to communicate with it. Today, social media platforms such as Twitter and Facebook allow the development of virtual customer environments (VCEs) in which specific businesses, brands, or products form online communities of interest. The advent of Internet-based SM has allowed everyone to interact about specific 


\section{International Journal of Social Science and Economic Research}

ISSN: $2455-8834$

Volume:06, Issue:06 "June 2021"

goods and the businesses that supply them with literally thousands of individuals. Therefore, in the industry, the effect of consumer-to-consumer contact has been widely magnified. Social media is a hybrid aspect of the advertising mix because it lets businesses communicate to their customers in a conventional way, although it only helps customers to connect directly to each other in a non-traditional sense. Monitoring the content and media-based conversations between users is also directly under the influence of outside managers. This contrasts with the traditional model of marketing relations, where a high degree of control occurs. Managers should also learn to influence customer conversations in a manner that is aligned with the purpose and success goals of the company. Most companies need to closely track and evaluate both the customergenerated content on their own social media pages and the textual details on the SM sites of their rivals to improve competitive advantage and effectively enter the competitive landscape of companies. The aim is to find the necessary information and apply it for trend analysis and prediction from this complex data. The application for social networking is not simply related to customer relationships, but it depends on the market, priorities, etc., and managers have to select their own techniques. Finally, some have attempted to standardize the deployment of enterprise SM networks by developing some necessary instruments.

Businesses also need to consider what the right social media sites are for their company before they can start putting together a game plan for social media management. Here's a short rundown of the various channels and what advantages an organization can provide:

Facebook- Facebook has almost 2.7 billion active users per month who come from different backgrounds. When it comes to Facebook's user base, there is also a nice mix between genders and age groups. For organizations that are seeking to reach a larger audience, this makes it a perfect social forum.

YouTube- YouTube has been the world's second largest search engine, second to Google alone. To help interact and communicate with audiences, companies can upload their video content to this channel. The company can upload as much video content as you want to and distribute across other platforms with unrestricted video hosting.

LinkedIn- LinkedIn is the social media site for B2B brands targeting companies in various sectors. With LinkedIn, businesses can search, connect, and share content with individuals based on the type of business, sector, or job title.

Twitter- Twitter has 321 million global active users and appears to be where news and trends go for users. This forum is perfect for brands who want to engage their industry in a dialogue about trending subjects. It's also a great place for influencers and other people who may find their brand valuable to share content. 


\section{International Journal of Social Science and Economic Research}

ISSN: $2455-8834$

Volume:06, Issue:06 "June 2021"

Wikipedia: Wikipedia is a free Web-based encyclopedia in which users can collaborate to prepare pages that provide data on any particular topic. It is also the root of the "Wiki" web technology, which describes the social media method of collaboratively building and updating a Web-based information. Today, several similar types of such technology allow users to work collaboratively on the Web to create knowledge-related content.

Google Plus: The social media environment supplied by the Google Corporation is Google Plus. Similar to other large social networking services such as Facebook or LinkedIn, this service uses the same user profile approach to allow users to exchange information and connect socially with other users through the Web/social media environment.

Mendeley, Academia, ResearchGate: There are also academic-oriented social media services on the Web that can be used by scholars, researchers and scientists to build their own profile and share academic work, thoughts on specially built Web interfaces. All of these services are intended to provide an efficient forum for knowledge sharing and communication, especially for individuals in academic and scientific fields.

Instagram: Instagram is an environment for social media in which users can share images or videos via their account. It is possible for Instagram users, like other social media sites, to like and comment on images posted on their accounts by other users. Instagram is also a smartphone application linked to the Web interface, so users can take photos, capture videos and post them over the Web using the application.

Another great channel to share image-focused content is Pinterest- For customers who are interested in DIY, art, home renovation, diet, health, fashion and more, this has become a must. If a product or service that lends well to imagery is offered by a brand, then Pinterest can be worthwhile.

The information that people generate is social media. It is a collaboration of people who exchange ideas and opinions that Tim Berners-Lee described as more than a browsing medium. Twitter, a free micro-blogging social networking site that allows registered users to broadcast short posts and follow tweets, is a good example. On the other side, Facebook, Google Plus, enables users to post ideas, photos, videos, and will allow anyone from friends of users to comment, share, like post. Social media offers the potential market and an opportunity to create a perception of the company, thereby creating prestige, brand, logo, and reputation. The number of users of social networking sites makes it attractive to move into social media for advertisers and organizations alike. For instance, Facebook has about 2 billion users across the globe. An advertisement on such a large website will reach a huge audience, making it at the forefront of business decision-making at relatively low costs. 


\section{International Journal of Social Science and Economic Research}

ISSN: $2455-8834$

Volume:06, Issue:06 "June 2021"

Online marketing, also referred to as internet marketing, involves the creation of blogs, blog marketing, email marketing and article marketing, and the promotion of a brand, service or product on the internet that incorporates the technological and creative aspects of the World Wide Web. Social media marketing and online marketing are also used interchangeably, but social media marketing is a part of online marketing, although they are not the same. Online marketing has been a valuable method for entrepreneurs as well as companies or small business owners. Whereas marketing of social media is carried out via social networks, i.e. Facebook, Twitter; Via contact with other members of these social networks, social media marketing helps to build company and customer connections. YouTube is popular for video marketing, as it is becoming a social networking platform, and is also considered part of social media marketing. YouTube is an outstanding platform for your target audience to advertise your goods and services.

Under the conventional approach adopted by management, it was considered essential only to shareholders of an organization. However, in order to achieve long-term sustainability in any company, under stakeholder theory, all associated parties such as clients, staff, vendors, general public, etc. must be satisfied. Hence, as per the approach of the stakeholder, all the parties concerned, connected to the social media marketing business, should be able to meet their needs through the online activities carried out by the marketing company. In establishing relations with the company's numerous stakeholders, social media plays a significant role. Therefore, social media channels are used by businesses to provide customers with accurate information about the company's goods and services. For example, through social media channels, companies communicate information related to significant business events or special price discounts. On the other hand, businesses will meet the majority of stakeholders within a short span of time with the aid of social media networks. Since customers are considered one of the organization's most significant stakeholders, social media has eased the way customers and the business interact. Consumers may express their satisfaction and concerns with the aid of social media platforms about the specific goods and services provided by the company.

The need to build product differentials and long-term sustainability is also important to consider when selling products through online channels. A large number of marketers would be interested in opting for these channels with the easy availability of advertising and selling goods through online channels, resulting in an increased level of competition in this medium. With the aid of social media networks, businesses are able to accurately determine consumer desires and expectations. Therefore, it helps businesses to develop goods and services in a way that suits their customers. It can be argued that social media networks have enabled businesses to retain competitiveness by addressing consumers' evolving patterns. On the other hand, it can also be claimed that businesses can develop personalized products that allow them to build product 


\section{International Journal of Social Science and Economic Research}

ISSN: $2455-8834$

Volume:06, Issue:06 "June 2021"

differentiation and gain competitive advantages by collecting information about customer feedback.

Though the negative effects of social media marketing could affect the organization's brand and affect the organization's overall output. It is a new age of advertising where there is a change of power from the manufacturer to the buyer, customers can now actually communicate their complaints either negatively or positively while at the same time making it known to millions of potential customers, making customers the driving force of organizations. Marketers are now facing the task of rethinking the way they connect with potential customers. On the internet, people feel free, it gives them the ability to express themselves and usually without repercussions, making it one of the variables that make social media marketing volatile and uncontrollable because you can't stop people from sharing their thoughts. Websites for social networking allow people to connect with each other and create relationships. Consumers can connect with them as businesses enter social media and they can communicate directly with customers, which interaction feels more intimate to consumers than conventional methods of purely outbound marketing and advertising. This engagement will instill in followers and potential clients a sense of loyalty.

Often, goods can hit a very small target audience by selecting whom to follow on these pages. According to research, organizational success involves an organization's actual production or results as calculated against its expected outcomes or objectives and goals. A performance measure is a given technique to observe an organizational performance attribute. This approach determines what, where, and how data on a particular performance attribute chosen for the purpose of performance evaluation will be obtained. A comparison of performance data between observed performance at an earlier time (before social media marketing) with a performance criteria such as an objective, aim, norm or a previous performance duration should be made in order to analyze performance data (after social media marketing). The era of catchy punch lines and striking visuals has not only had an impact on companies but on marketing itself; it is about constant dialogue, building confidence and communicating with the right audience in the right way, as quickly as possible, marketers are now at the front of the line facing customers and managing the brand.

Although celebrities such as Selena Gomez are potential influencers for major brands, these typical celebrities are so costly that smaller brands have started and will continue to capitalize on the popularity and success of what are known as "micro-influencers," representing a new class of influencers. Micro-influencers are influencers who are not as well-known as celebrities, but who are typically more targeted and have large and enthusiastic followings, ranging from a few thousand to hundreds of thousands of followers. These types of influencers are commonly perceived to be more trustworthy and credible than conventional celebrities, which is a 


\section{International Journal of Social Science and Economic Research}

significant reason why influencer marketing has become more and more desirable to brands. In what they post about, these people are also seen as trustworthy "experts," inspiring others to want to access the content they produce and engage with them. In addition, the use of these influencers allows the brand to narrate through first person narration (compared to advertising), which is considered warmer and more intimate, and has been proven to be more effective in engaging customers. Considering the potential reach and involvement of social media influencers, businesses have either started to accept social media influencers, or plan to broaden their efforts in this area even further. In recent conversations we had with social media executives, for example, some of them stated the increasing value of influencers and listed how brands usually aim to integrate influencer marketing into their marketing strategies. In addition, recent interviews with executives at some of the world's leading brands show that major brands' influencer marketing spending continues to grow. Although social media influencer marketing is not new, research believes it has a lot of potential to further grow as an industry.

Companies need to recognize social media threats, develop robust risk-mitigation governance policies, and then implement the best technologies to improve those policies. Risks of social media include

Human Error: In this age of communicating directly with the public, errors are expected to happen in real time. Employees can also be hacked because they believe their "tribe" of social media users' fellow members may be fooled by fraudsters.

Processes: Before they get started, organizations need to identify and authorize the necessary permits, approvals, access, data classifications and collaboration processes.

Legal: Possible concerns vary from privacy law enforcement, copyright rights, violation of intellectual property, to human resources issues such as illegal practices such as abuse, discrimination and defamation.

Compliance: Regulations for industry vary according to industry, geography and culture. In the US alone, there are more than 10,000 laws and regulations regulating electronic communications. Regulatory categories include recordkeeping, adherence to advertisement standards, and employee supervision. When regulators perform audits as well as respond to ediscovery queries, companies must be able to provide evidence of enforcement.

Financial: Missteps may have a negative effect on share prices and lead to fines from regulators or law enforcement authorities for data security.

Operational: While social media can be a competitive advantage, it can be disruptive and reduce the productivity of employees. 


\section{International Journal of Social Science and Economic Research}

ISSN: $2455-8834$

Volume:06, Issue:06 "June 2021"

Data (collection, privacy, security): Businesses need to comply with regulatory requirements relating to data collection, processing, handling and storage. To prevent sensitive clients and other data from leaking out, or even into, the enterprise, the corporate network should be protected. When social media users unintentionally inject malware into the company or workers are attacked by cybercriminals, the firm should be shielded from incoming threats. As workers communicate with each other and exchange documents across borders, global companies need to comply with local data protection regulations

Reputation: Material is generated outside of the firewall in real time, with the associated reputational risks. Mistakes and hacks may have a negative effect on the brand and the loss of trust of staff, customers, or investors.

ROI: For management, metrics for performance need to be identified in advance. Executives predict increased production and investment returns.

Costs: While social media is considered open, businesses will need to employ consultants to work on their governance problems, third-party providers to provide access control platforms and maintain records, and writers or agencies to produce content.

Bandwidth: To create, administer, supervise and modify both internal and external social media systems, resources are needed. It's important to build content. Departments that may include corporate affairs, marketing and enforcement will review changes.

Via good governance and risk management, the business will get the most out of social media in light of these risks. In reality, governance is all about how a firm runs social media, it's policies and procedures, and how it's aware of the threats and how to handle them. Multiple groups within a company, such as Marketing, Customer Care, IT and HR, are affected by social media. Such groups have different positions and also different opinions about how to use social problems. Good governance brings together those individuals to ensure that the plan for social media matches in with the overall business strategy. Keep away from long, boring policies, and instead build engaging policies that inspire workers to use social media. If more workers start embracing and relying on these new ways of working, to avoid disrupting the business, technology needs to be reliable. To fix technology problems efficiently, processes should be placed in place. Companies will need crisis management strategies that detail what to do in a crisis when anything on social media goes wrong and how to use social media.

And then the enforcement is there. Companies need to figure out how their business can comply with different local and sector laws and regulations, including privacy and security of data, advertising, record keeping and oversight. They need to identify the priorities and strategy for implementation, including policy awareness and training, for companies preparing to deploy 


\section{International Journal of Social Science and Economic Research}

ISSN: $2455-8834$

Volume:06, Issue:06 "June 2021"

social enterprise platforms. In an organisation, not everyone is social. They need to consider designing training programs to encourage their workers, while reminding them of the risks, to be socially confident. A very important point in governance is to incorporate the right habits from the beginning. Governance on social media is all about how to do better with social media. This isn't just about policy. It sets the necessary operational processes in order to ensure that the right approach is used socially. In short, to handle social media systems and integrate corporate governance into the framework of data processing, technology should be used. It is possible to use technology to set business rules, handle approvals, hierarchies, and chains of approval. In countries around the world, technology can also resolve data storage and processing regulations and essentially mimic the enforcement requirements of a business. But it is important to consider all the risks and act on them accordingly.

Social networking is also among the 'best possible possibilities' for an item to get in touch with potential buyers. Public platforms for social networking are the way to publicly connect. By linking with them at a deeper level, these new media gain the trust of clients. Group online marketing has been the latest mantra for many manufacturers since the beginning of the previous season. Promoters are looking at several different possibilities for social media and are starting to introduce new social ventures at a faster pace than ever before. Group web marketing and the enterprises that use it have become more advanced. If the rival is making waves with its solutions and goods, one can not afford to have no presence on the social programs. The explosion of the trend in social media is as remarkable as that and it is disappointing at the pace at which it is changing. International businesses have established social media promotion as a possible advertising system, using it with modifications to encourage social media promotion in their marketing.

In the integration process of the different social media tools, there are a large number of issues present. Businesses can make the mistake of creating an unstructured approach rather than creating a strategic perspective. It is necessary to illustrate the company's marketing or advertisement target for small-scale companies and then create the integration plan. The social media network is highly diversified in nature, and the influence of each instrument must be evaluated by marketers. Each tool for social media often caters to a particular form of user market that has distinct attributes. The organization is unable to establish a marketing strategy that does not resolve these major variables. Each tool for social media often caters to a particular form of user market that has distinct attributes. The organization is unable to establish a marketing strategy that does not resolve these major variables. The company also needs to improve the facility's technical infrastructure. The level of investment must also be focused on the corporate entity's long-term outlook. If the organization assumes that the customer market relies heavily on the online community, it must invest appropriately. The size of the organisation 


\section{International Journal of Social Science and Economic Research}

ISSN: $2455-8834$

Volume:06, Issue:06 "June 2021"

has an impact on the decision to invest. Some businesses have access to limited capital and are therefore reluctant to invest too heavily in technical infrastructure. The pace of advancement is another problem present in the investment stage. If businesses invest too heavily in technical infrastructure, the technology is at risk of being redundant. The technology is rapidly evolving and a small-scale business should not invest too much money in the process of technological growth that does not have long-term returns. Therefore, in the social media-related technological investment process, there are many variables that must be addressed by businesses.

The company's social media development strategy would help the organization establish a stronger relationship with the customer market. It can also be described as an essential opportunity to improve the role of customer service. The operations of customer services are focused on the organization's ability to communicate with and offer immediate assistance to customers. For today's organisations, the social media network is a perfect solution that can be used to provide the user base with cost-effective and timely support. Companies need to evaluate the characteristics of the consumer market on social media and improve exposure on the related websites. The value of social media as an important customer service platform has already been understood by the majority of organisations present in the contemporary business climate. The explanation for the corporate entities' social media-oriented initiative is to ensure that customers can access help in a highly tailored and convenient manner.

Social networking has an efficient and impressive role in today's marketing strategies. It can be expressed that the popularity of social media services in marketing operations in particular has tremendous potential for the future, thanks to the ongoing rapid developments in computer and communication related technologies. In order to strengthen the brand-company from various viewpoints, the above are examples for recognizing the effect of social media in businessoriented works and assessing the performance key points. It is definitely possible to reflect on several different examples of social media marketing applications. At this point, it is crucial to have an understanding of the variables that influence the performance of social media marketing and make it easier to enhance the brands themselves.

\section{RATIONALE}

The process of developing, posting, and reviewing content you share on social media sites such as Facebook, Instagram, and Twitter, as well as communicating with users on those platforms, is social media management. With free and paid software, as well as professional social media management providers, you can streamline social media management. For several company leaders, the idea of Social Media was at the top of the agenda. Decision makers, as well as experts, aim to find ways in which businesses can use apps such as Wikipedia, YouTube, Facebook, Twitter, etc. profitably. Consumers have historically used the Internet to invest 


\section{International Journal of Social Science and Economic Research}

content simply, and used it to purchase goods and services. This illustrates the phenomenon of social media, which can now dramatically affect the credibility, revenue, and even survival of a business. Although thousands of studies have previously been carried out to study different facets of social media in regards to business management, this subject is as far from being exhausted as a field of science. Specifically, new research may be carried out to examine the influence social media has on various business related activities and more such impacts. To fill this gap, I have picked up this topic to conduct my research upon. Alternatively, the implications of social media on business management can be extensively analyzed. In almost all fields of business studies, the same concept applies, i.e. holes in the literature can be found in almost all areas of business and economics. This research talks about the critical analysis of how different social media networks function in respect to business management, their benefits and implications, and other impacts of networking tools. It's not just focused on one aspect but carries widespread research. The reason for selection includes my own inclination towards the topic of social media. Every teenager today spends most of their time on social apps, me being one of them. I have always noticed the role it plays for various businesses in terms of advertisements and many more such factors. This intrigued me to dig deeper into how this social media acts in the perspective of management studies. Moreover, I am a highschool student and I wish to pursue a career in business management and am hoping and willing to study a management course and obtain a degree. I aspire to become something in the same field. Therefore, conducting research on this topic has also given me insight to the real and practical world, and lots of knowledge that will definitely help me in my future endeavours.

\section{REVIEW OF LITERATURE}

Mr. Andreas Kaplan from ESCP Business school conducted research on the topic "Users of the World, Unite! The challenges and opportunities of social media." in 2010. They relied on a number of theories in the field of media science (social presence, media richness) and social processes (self-presentation, self-disclosure), the two main elements of social media, to establish such a classified research paper and to do so in a systematic way. The whole paper was based on numerous other studies performed in the past. Social media is defined, according to Kaplan and Haenlein (2010), as a community of Internet-based applications built on the ideological and technical foundations of Web 2.0. This enabled the manufacturing and exchange of the

Content that users create. Web 2.0 is a software for social purposes whose importance is created by the volumes of individuals who use it to collaboratively create and distribute information. A detailed list of resources that fall under this category will help to realize the existence of an exact description of the concept of social media. But the focus on teamwork was reinforced by a general agreement on the technologies that belong to the Software 2.0 Web development age. 


\section{International Journal of Social Science and Economic Research}

ISSN: $2455-8834$

Volume:06, Issue:06 "June 2021"

Weblogs, wikis, RSS techniques, social networks, mashups, podcasts, folksonomies, or virtual worlds are among these.

Mr. Simeon O. Edosomwan from North Dakota State University conducted research on "History of social media and its impact on business" in 2011. The authors describe features and the evolution of social media in this article, including significant social networking sites that came into being during the 21st century. Using theoretical analysis methods, some of the sites discussed include Facebook, YouTube, Twitter, MySpace, CyWorld, and LunarStorm. According to the research, Social media is a modern version of networking used in the 21st century by individuals with the aid of the internet as a medium. Without the restriction of distance, it hits vast numbers of individuals all over the world. It has also become a highly productive instrument for corporations to connect with customers. Social networking is the foundation of social media knowledge and before understanding social networking, it was difficult to think about social media. How the telegraph was used to relay messages in the $1700 \mathrm{~s}$ over a long distance.was an example given in the article. This has now become a reality in which users interact using networking tools such as Google buzz to help users in discussions, exchanging images, messages, videos and their views on a particular topic.

Jan Kietzmann from University of Victoria, Kristopher Hermkens from Simon Fraser University, Ian Paul McCarthy from Simon Fraser University and Bruno Silvestre from University of Manitoba conducted research on "Understanding the Functional Building Blocks of Social Media" in 2011. The study proposed a structure using seven functional building blocks to describe social media: identity, conversations, sharing, presence, relationships, reputation, and groups. Since the degree to which they rely on any or all of these blocks is determined by various social media practices, they clarify the consequences that each block may have on how businesses can interact with social media. For the purpose of developing these strategies, they presented the guidelines in form of 4Cs- cognize, congruency, curate and chase. In the honeycomb system, businesses interested in being serious about social media can find a helpful method by developing a congruent social media strategy. In conclusion, the research offers a set of guidelines about how businesses can develop strategies to track, understand and respond to various social media activities.

Guarav Seth from University of Nevada, Las vegas conducted research on, "Analyzing the Effects of Social Media on the Hospitality Industry" in 2012. By comparing a variety of research from scholarly journal papers and other sources of research-intensive literature, this research paper was compiled. According to the research, The disparity between social media and conventional media was the difference between user engagement in social media. Social and conventional media are used to reach consumers; the only media that encourages customers to 


\section{International Journal of Social Science and Economic Research}

ISSN: $2455-8834$

Volume:06, Issue:06 "June 2021"

engage and disseminate their views is social media. Social media analysis indicates that nearly 50 percent of adults who use the internet

are interested in social networking, suggesting that this figure has a huge effect on corporations. Marketing firms use customized tools for data mining that helps them to keep track of customer behavior, patterns of purchasing and satisfaction scores. These results were used to calculate the efficacy of the Return on Investment (ROI) and other success metrics of marketing campaigns.

Stephen J. Andriole from Villanova University conducted research on, "Business Impact of Social Media Technologies" in 2010. In the research paper, the question, "What do wikis, blogs, podcasts, social networks, virtual worlds, and the rest do for corporate productivity and management?" was explored and research was performed and evaluated and interpreted using statistical methods such as bar graphs. Business skills play a major role in enhancing the efficiency of companies, according to this study. The paper identifies six variables (business capabilities) that are affected by the use of social media tools, as shown in their analysis, and ultimately affect business efficiency. These six variables, informed by the use of social media, contribute to organizational capabilities. Usage of social media technologies based on the company's resource-based view can boost organizational skills and, eventually, the success of companies. The 6 factors included collaboration and communication, rapid application development, customer relationship management, training, innovation and knowledge management.

Martin Smits from Tilburg University, Netherlands, conducted research on the topic, "The Impact Of Social Media On Business Performance" in 2013. The aim of this research was to examine the influence of social media and to evaluate the degree to which organizational capabilities and business performance are influenced by social media. They developed a model of research and two basic propositions based on the company's resource-based view. The paper examined the effect of six social media applications in the online game advertising industry since 2009 on six business capabilities and the business output of SponsorPay, a start-up company. It used a mixed research approach that included interview-based qualitative analysis and quantitative analysis among 60 employees based on a survey. Their research showed that market skills and business efficiency were improved by the use of social media. The effect is not due to just one (out of six) social media tools, but due to the efficient integration of the six social media tools into one powerful social media ecosystem that allows internal and external business processes to be organized.

Rajiv Kaushik, Ministry of External Affairs Govt. of India conducted research on "Impact of Social Media on Marketing" in 2012. According to the research, websites for social networking allow people to connect with each other and create relationships. Websites for social networking, 


\section{International Journal of Social Science and Economic Research}

ISSN: $2455-8834$

Volume:06, Issue:06 "June 2021"

including Twitter, Facebook, Google Plus, YouTube and blogs encourage individual followers to re-twddg or repost comments created by the promoted product. Other aspects of social media marketing and related concerns and criticism were discussed based on completely theoretical research from well known journals and other research. The research paper concluded with the conclusion that as the prevalence of social media is rising and there is no going back, it seems that social media will largely overtake other usable marketing fields. Via constant dialogue, building trust and engaging with the right audience in the right way, as soon as possible, social media aims to fill the gap between advertisers and customers.

Robert Effing of Saxion University conducted research on, "Social Media strategy design" in 2013. A systematic analysis of literature was undertaken for research. The study was systematic because the methodology, the collection of the items and the meta-information are straightforward. According to the research, It appears that social media is evolving, From the lowest to the highest level of management, the way we do business and how leaders are viewed. Interestingly, while in this field the best organizations are developing systematic strategies, research shows that few business leaders have a presence in social media and those who do not use it strategically. It talks about why social media should be used in today's world because They have a fully open platform that is low-cost. They make it possible to communicate with friends, staff, clients, and the wider public easily and concurrently in order to exploit relationships, to demonstrate commitment to a Reason, and show a capacity for reflection. And they have an opportunity to learn from immediate data and unvarnished reviews. However, the system is not an opportunity to produce bureaucracy.

In 2018, Mias De Klerk of Stellenbosch University conducted research on the topic, "The impact of social media on recruitment". This research explored the effect of social media on South Africa's recruitment process. There were 12 recruiters in the study, covering a large variety of industries in South Africa. In order to define themes and subthemes, semi-structured interviews were performed and a thematic analysis was used. The study suggests that social media should be used in recruiting and incorporating certain company knowledge in addition to socializing. It also mentions that business organizations which do not accept social media such as Facebook, LinkedIn, Twitter for recruitment purposes may lose competent candidates.

Tina P. Singh, and Dr. Ratna Sinha, ISBR Research Centre, Mysore University, Karnataka, India conducted research on "The Impact of Social Media on Business Growth and Performance in India" in 2017. The study understood the advantages, effect and significance of social media on business performance and growth. The six main benefits included Improved consumer insights, Better customer service, Cost efficient, Connectivity, Establishing brand awareness and Increase in sales. A case study of McDonald's was also provided with later discussing how social media could be used as an effective marketing tool. The study also shows that social media has a 


\section{International Journal of Social Science and Economic Research}

ISSN: $2455-8834$

Volume:06, Issue:06 "June 2021"

beneficial effect on business as well as growth and success. Companies, according to it, should embrace social networking at the stage of maturity in the product lifecycle to prolong their market longevity, and if they fail to do so, they will inevitably go downhill in the coming years.

Soumitra Dutta published research in Harvard Business Review magazine in 2010 on the topic, "What's Your Personal Social Media Strategy?". The study says that social media, from the shop floor to the CEO suite, is changing the way we do business and how leaders are perceived. But while the best companies are developing comprehensive strategies in this field, research indicates that few business leaders have a social media presence-say, a page on Facebook or LinkedIn-and that those who do not use it strategically. Today's leaders must embrace social media for three reasons. First, they provide a low-cost, highly accessible platform on which a personal brand can be built, and also communicates our identity within and outside the company. Second, they allow them to engage rapidly and simultaneously with peers, employees, customers, and the broader public-in order to leverage relationships, show commitment to a cause, and demonstrate a capacity for reflection. Third, they give an opportunity to learn from instant information and unvarnished feedback.

Pekka Aula from the Finnish Academy of Science and Letters conducted a research on, "Social media, reputation risk and ambient publicity management" in 2010. The study focuses on the danger and risk to the credibility of business organizations from social media. It mentions examples of events where the power of social media is involved and how ads can have a negative effect on a company's image. It points to the most common and fascinating corporate-based social media platforms, including Facebook, MySpace, and Twitter. It also talks about 9 tenets for leaders and four reputation strategies for reputation including strategy of absence, presence, omnipresence and attendance. It states, however, that social media extends the reach of reputational hazards and increases risk dynamics.

Michael L. Kasavana from Michigan State university conducted research on "Online social networking: Redefining the human web" in 2010. While it is relatively new to incorporate online social networking within the hospitality industry, its criteria have unique consequences for constituencies in the hospitality industry, including clients, staff members and management. The goal of this paper was to explore the evolution, scope and types of social networks online and the possible consequences for hospitality companies. This paper is focused on an in-depth literature review, including expected and unintended social media implications. Although social networking can enable a hospitality business to reinforce guest loyalty and satisfaction, according to the report, it can also expose itself to unfair criticism and baseless speculation. In addition, in an effort to promote interactivity by promoting peer-to-peer and staff-toadministrator interaction, several hospitality companies have funded coworker sites, only to risk exposure to negative relationships and strained working conditions. 


\section{International Journal of Social Science and Economic Research}

ISSN: $2455-8834$

Volume:06, Issue:06 "June 2021"

Vivek Bajpai, from CV Raman University, India conducted research on, "Social Media Marketing: It's strategies and impact" in 2012. This study highlighted social media, which helps to connect with social networking sites through which people can now stay far away and remain connected. Intense research from literature was done for this research and it gave various strategies for small businesses and related case studies. Facebook, in addition to this media, creates a loyal connection between product and person that leads to large advertising opportunities. Similarly, other social media such as blogs create a platform for posting a comment on any event that needs to be advertised can also be used as a promotional method for the adoption of customers as well as for promotions. According to the study, you reward and remind them that you are not only a brand to engage with, but also to buy from, offering exclusive coupons to your social community. Taking advantage of these approaches can help companies build their community, make their advertising more efficient, and encourage buying.

Mohammad Yousef Abuhashesh from Princess Sumaya University for Technology in 2014 carried out a research on, "Integration of Social Media in businesses". Prior research was critically analyzed to put together this research paper. It emphasizes a lot on small businesses, initiatives and strategies for them. The study says that social networking in the lives of some users has become a daily practice. The authors describe social media features and trends, including significant social networking platforms that came into being during the 21 st century. The doctoral student's research work reported that the company's management must build the necessary organizational skills to ensure that the process of social media incorporation is successful and that the core role can be improved, such as labeling, advertisement, public relations and customer services. According to the research, Corporate organizations present in the modern market climate must ensure that social media platforms are incorporated.

Vilma Aturi from New York Business School researched on the topic, "Social Media Analytics: The Effectiveness of Promotional Events on Brand User Base in Social Media" which is still in progress. This paper studies a groundbreaking social media venture and aims to analyze its effects on participating brands to understand the efficacy of advertising events on social media channels. It uses a promising analysis technique based on the methodology of event study and uses a rich database consisting of all promotional activities by American Express Company and its participating partners on Twitter. Through this research, it was noted that the majority of businesses use conventional and social media combinations to meet their consumers. The use of social media has been shown to help businesses reach out to more consumers and better address their needs. By using social media, companies have seen an increase in their brand recognition and brand image.

Sandeep Bhanot from SIES College of Management Studies, India, researched on, "Impact of Social Media on company performance" in 2019. It found out that the majority of the companies 


\section{International Journal of Social Science and Economic Research}

ISSN: $2455-8834$

Volume:06, Issue:06 "June 2021"

are using social media to reach out to their customers. It is also helping in Enhancement of their brand awareness and brand image by use of social media and social media also acts as a Gold mine for brand building. According to research Social networking is not just about contact, but also about user engagement. The most important characteristics include openness, community, connectedness and a community. Extensive research of literature has been used to design this research paper and has covered all the aspects of social media's positive effect on the performance of a company or a brand discussing its various features, benefits and case studies which have previously proven to be successful.

Farzana Parvee, University of Malaya conducted research on the topic, "Impact of social media on organizations" in 2012. It observed through interviews conducted by top companies and stated that the qualitative approach was used to define the variables influencing the use of social media and its effects on organizations. Of the 36 organizations that successfully use social media, six organizations were chosen. There have been semi-structured face-face interviews. A general interview guide was used where, in outline form, the subjects and issues are defined in advance; during the course of the interview, the order and wording of questions were changed. Interviews, on average, lasted about an hour and were documented and subsequently transcribed. In most organizations, social media comes from either the department of marketing or corporate relations, except for one company with its own department of social media. According to this report, the social media department is either marketing or corporate relations. Social networking is used as a contact tool for corporate companies and public bodies. And, in corporate practice, social media has been identified as the most potent medium.

Laura Matthews from Elon University conducted a research on, "Social Media and evolution of Corporate Communications" in 2010. This study was described as a critical review and interpretation of recent research findings, trade journals, online technology, case studies, current developments, theories of public relations and literature on academia. The goal of this study was to define aspects of conventional public relations and aspects of public relations using social media, and to examine the changes that have taken place within the industry and make predictions for the future through contrast. According to the report, social media helps to move from conventional corporate communication methods to the use of public relations in an industry. Social media will continue to build corporate networking habits and improve them. In addition, it provides opportunities for constructive discussions, effective campaigns and the realization of ideals for the industry. The public relations industry has grown rapidly from unchanging, conventional approaches to accommodate continuous change and new instruments, generating possibilities for constructive conversations, effective campaigns and the realization of industry values. 


\section{International Journal of Social Science and Economic Research}

ISSN: $2455-8834$

Volume:06, Issue:06 "June 2021"

Efthymios Constantinides from University of Twente, conducted research on the topic, "Foundation of Social Media Marketing". The study describes the essence, effects and current status of Social Media, underlying their role as agents of consumer empowerment. As part of the corporate marketing plan, it describes their aptitude and potential positions and discusses multiple ways to engage them as marketing tools. The study suggests two potential marketing strategies for social media: the passive approach that focuses on using the domain of social media as a source of consumer voice and business intelligence. And, the successful strategy is to include social media as direct marketing and PR networks, as customer impact channels, as tools for personalizing goods and, last but not least, to develop them as collaboration and customergenerated innovation platforms. Finally, the paper identifies potential research directions for this new marketing environment aspect. The study's most significant message is that marketers should recognize that the future marketing model is based on transparency, collaboration, cocreation, and an honest dedication to listening to and supporting rather than influencing the consumer. Social media is an agent of change and a source of opportunities for marketing strategists who learn to work in a modern business climate that puts the client at the top of corporate priorities again.

Nina Eyrich, Monica L. Padman, and Kaye D. Sweetser from University of Georgia researched on the topic, "PR practitioners' use of social media tools and communication technology". Using an online survey, the study aimed to provide an academic basis for social media adoption as a whole (beyond blogs), industry opinion on these tools, and its strengths. The study found that social media technologies help PR professionals to reach and engage their audiences in dialogue and provide an opportunity to improve media ties, and that a majority of practitioners believed that communication technologies such as social media made their jobs simpler, enabling them to reach wider audiences and speed up the flow of information. On average, survey respondents used 5.97 of the 18 social media tools listed in the survey, followed by intranets, blogs, videoconferencing and podcasts, with e-mail, a long-established tool, being the most commonly used. As one of the first academic studies to include data on the overall acceptance of social media, this brief study offers a short overview of industry adoption trends.

Ester S. Gonzalez of California State University conducted research on, "The impact of internal social media usage on organizational socialization and commitment" in 2013. The aim of this study was to investigate an internal social media tool that as part of a new hire program was planned and introduced. IT new hires in a military financial services company were administered an online survey. Although the use of social media related to work has not shown a substantial association with socialization or involvement, this study indicates that the use of social media related to social media is connected to awareness of organizational culture, social acceptance, and affective engagement. Two forms of social media use, four socialization indicators, and three 


\section{International Journal of Social Science and Economic Research}

ISSN: $2455-8834$

Volume:06, Issue:06 "June 2021"

engagement indicators were evaluated in this analysis. This paper concludes with a debate on the consequences of the usage of internal social media.

Sanjukta Pookulangara from University of North Texas conducted a research on, "Cultural influence on consumers' usage of social networks and its impact on online purchase intentions" in 2011. A research model using Hofstede's cultural dimensions and Technology Acceptance Model 3 was introduced in this conceptual paper to explore the cultural effect on social networking and its effects on the intention to buy. The study concluded that culture actually affects how people behave on technology-based apps, such as social media, and view an event. This implies that the cultural or ethnic context of a person will impact how they will view social media and its content. Retailers need to be mindful of the value of because social networks are a fusion of various cultures and the development of new online cultures, while using social media. In addition, cultural backgrounds and traditions can factor into the formulation of a consumer's opinion and attitude towards a brand or product.

Fotis Kitsios from University of Macedonia researched on "The influence of social media on consumers' behavior" in 2017. The collection of data was performed via an online questionnaire addressed to users of social media. In order to complete the query, the basic requirement was for subjects to have at least one active account on any social networking site. Upon analyzing the research, a conclusion was made. As social media can impact the decision-making and buying strength of consumers, executives have the ability to hold discussions in order to market their goods. Companies have the ability to promote their products, their image and overall presence on social media through virtual engagement with customers to meet the needs of consumers. If a business succeeds in getting happy customers, the image of the company would in turn be widely distributed, creating a positive atmosphere around the brand of the company. Thus, clients are drifting into buying company goods through favorable referrals relevant to the company.

David J Faulds from University of Louisville researched on, "Social media: The new hybrid element of the promotion mix" in 2009. This research suggests that social media is a hybrid part of the advertising mix because it allows businesses to speak to their customers in a conventional way, while it allows customers to talk directly to each other in a non-traditional sense. Outside the direct control of managers are the content, pacing, and frequency of social media-based conversations between users. This contrasts with the conventional model of integrated marketing relations, whereby a high degree of control is present. Managers must also learn to influence customer conversations in a way that is compatible with the purpose and success objectives of the company. Methods by which this can be done include providing networking sites for customers, including using blogs, social media resources, and customer engagement promotional tools. 


\section{International Journal of Social Science and Economic Research}

ISSN: $2455-8834$

Volume:06, Issue:06 "June 2021"

Mesut Çiçek from Washington State University carried out research on, "The Impact of Social Media Marketing on Brand Loyalty" in 2012. The scope of the study consists of clients who follow at least one social media brand in Turkey and the data was collected through the administration of a standardized 338-person sample questionnaire and evaluated through multiple regression analysis step-by-step. The results of the study showed that consumer brand loyalty is positively influenced when the brand offers beneficial campaigns, provides appropriate content, provides common content, appears on different channels and offers social media applications. Customers on social media sites tend to share music, technological-related, and humorous content. This research can be regarded as a leader in this new marketing field on the basis of the findings, and recommend some strategies for the practitioners.

Andrew T Stephen from University of Pittsburgh wrote an article on "The Effects of Traditional and Social Earned Media on Sales" in 2012. This research explored how two forms of media received, conventional media (for example, ads and press references), and social media (for instance blog posts and online group posts), influence sales and behavior. A multivariate, autoregressive time series model was used to evaluate 14 months of daily sales and media interaction data on a microlending marketplace website. The authors noted that both traditional and social media influence sales. The sales effect of traditional media activity per event is greater than for social media, but since social media activity is more regular, the social media elasticity is significantly higher after the event frequency adjustment than traditional media.

Venkateshwar Radhakrishnan from Salalah College of Technology conducted research on "Impact of social media application in Business Organizations" in 2019. This small study discusses the social media variables and key influences, benefits and drawbacks that influence business people to use social media in their business growth and efficiency. The interview mail forms are not yet completed, but it is revealed by observation and extensive literature survey that most businesses use a mix of conventional and social media to find out about their customers. It has been shown that the use of social media apps and tools has allowed businesses to brand their products more and attract more consumers with their brands and better meet their needs. By using social media, companies have seen an increase in their brand recognition and brand image. Based on these findings, there are many benefits but few drawbacks, but businesses can make better use of social media by keeping their message transparent, preventing confusion and ensuring that their online presence suits their brand image. Marketers regard social media, a space for many of their customers, as a gold mine for the growth and creation of brands and companies.

Roberto E. Montalvo, Ph.D., University of the Incarnate Word, USA conducted research on "Social Media Management". The paper concentrates on the impact of social media on the business world. It provides a view of recent activity in the recruitment of corporate social 


\section{International Journal of Social Science and Economic Research}

ISSN: $2455-8834$

Volume:06, Issue:06 "June 2021"

network managers and compares it with the recruitment of webmasters during the mid-1990s. The recruitment activity represents the increase in the time people spend socially online. It also explains how brand recognition and brand value are affected by social media management. The research was carried out by analyzing old literature extensively. It is only a matter of time, according to the report, until social media administrators are as ubiquitous as the network administrator and the network manager.At least a chapter, if not an entire course in social media management, should be included in the business curriculum and the next generation of Web 2.0ready managers should be created based on the study.

Mehdi Abzari from University of Isfahan researched on, "Analysing the effect of social media on brand attitude and purchase intention" in 2014. Using a self-administered questionnaire, 210 respondents were asked to respond to the survey using the method of comfort-sampling. Structural equation modeling findings suggest that conventional advertising and social media have a huge effect on the attitude of the brand. The influence of conventional advertising, however, was less than that of social media. In addition, brand attitude has a huge effect on the purpose of buying. The findings of this study showed that as social media can affect the decision of consumers to buy the company's product, managers should try to encourage customers to chat about the company's goods and services to each other. Via social media, such as chat rooms on Facebook, these discussions may be face-to-face or virtual. This means concentrating on improving the quality of goods and services. The referrals, in turn, will influence the decision of customers to buy a company's goods.

Khadije Abdipour from Iran University of Science and Technology conducted research on "The impact of social media in business growth and performance" in 2019. The research aimed to study the status and evolution of empirical studies on social media applications in industry. The technique for study was a scientifically applied approach using library methods and scientific metrics. It was a quantitative approach. This research analyzes and demonstrates the world's science products in social media and industry for 14 years. Studies started to expand more and more in 2014. But its steep growth slowed in 2018. A series of tables and maps showing the most cited countries, papers and so on were displayed. The findings show that the US has been a pioneer in publications of this subject with 1269 articles, and the Business Horizons Magazine has published 73 articles. The study of the contents of works created in social media and corporate applications will help us better understand the trend for growth in that field.

\section{RESEARCH METHODOLOGY}

Our method of research is both qualitative and quantitative and requires a retrospective review of the processes involved. Our research is not action research, since we were not involved in the design and creation of social media during the time frame studied and our results were not 
influenced by the design. An extensive review of literature will be an excellent way to synthesize research results to demonstrate facts at a metaphor level and the development of conceptual models. Employees of major corporations which use social media will be sent a questionnaire to gain an understanding of the manner in which the social media is interpreted and how its effect is viewed by employees in enhancing their business processes. In our survey questionnaire the efficiency of business processes will be measured using the self-assessment approach. Our study will depend on the observation and answers given by the survey. There will be a lot of respondents from different companies. The majority of research will be performed with the intention of exploring the efficiency of social media incorporation into the company's marketing, publishing, public relations and customer services functions as the purpose of this research is to qualify aspects of businesses utilizing social media, and through comparison to analyze the changes that have occurred within the industry and make projections for the future. In simple words, the objective is to find the role of social media in the perspective of business management. The responses will be then analyzed with the help of statistical tools and an analysis/conclusion will be made interpreting the results based on the observations.

\section{RESULTS}

A questionnaire was sent to employees of the corporate sector in order to be able to understand the way in which the Social Media applications are perceived and how their impact in terms of improving business processes is regarded by company employees. Over 50 respondents from various different companies participated in the survey.

\begin{tabular}{|l|l|l|}
\hline 1 & What company/organization do you work for? \\
\hline 2 & Which department do you work in? \\
\hline 3 & How long have you been working at the company? \\
\hline 4 & $\begin{array}{l}\text { Which social media tools do you use on a daily basis? } \\
\text { (Facebook/YouTube/LinkedIn/Instagram/Youtube/Twitter/Others) }\end{array}$ \\
\hline 5 & \begin{tabular}{l} 
How much does this tool improve your work? (On a scale of 1-10) \\
\hline 6
\end{tabular} & $\begin{array}{l}\text { To which business capabilities do you believe social media contributes the most? } \\
\text { Knowledge Management/Innovation/Training/Rapid }\end{array}$ \\
\hline
\end{tabular}


International Journal of Social Science and Economic Research

ISSN: $2455-8834$

Volume:06, Issue:06 "June 2021"

\begin{tabular}{|c|c|}
\hline & $\begin{array}{l}\text { Development/Collaboration and } \quad \text { Communication/Customer } \\
\text { Management/Others) }\end{array}$ \\
\hline 7 & Which social media has contributed most to each business capability? \\
\hline 8 & How satisfied are you with using social media tools in your company? \\
\hline 9 & $\begin{array}{l}\text { Rate how much your work has improved or become difficult since the introduction of } \\
\text { social media. (On a scale of 1-5) }\end{array}$ \\
\hline 10 & $\begin{array}{l}\text { How satisfied are you with receiving information from social media through your } \\
\text { customers about the company? (On a scale of 1-5) }\end{array}$ \\
\hline 11 & $\begin{array}{l}\text { Compared to other sources, do you believe information received through social media } \\
\text { about the company is the most acceptable or efficient? }\end{array}$ \\
\hline 12 & What's one challenge social media has caused you in your work? \\
\hline 13 & What's one major advantage that you believe you got through social media? \\
\hline 14 & $\begin{array}{l}\text { The level of campaign of my company (brand) in traditional media such as } \\
\text { television/radio has met my expectations. (On a scale of 1-5) }\end{array}$ \\
\hline 15 & $\begin{array}{l}\text { Would you like to continue watching your company use social media for different } \\
\text { business operations? (why/why not) }\end{array}$ \\
\hline
\end{tabular}

There was a diverse group of people who took part in the survey. Employees belonging to very different companies responded, some of the known ones being TATA, Reliance, Swiggy, etc. And not just Indian employees, we also had respondents from countries like the USA and the UK from Salesforce, webvirtue, etc. Out of all the respondents, $12 \%$ belonged to Human Resources, 36\% in the IT department, 16\% in Accounting and Finance, 20\% in Marketing department, and the remaining $16 \%$ of the employees in Research and Development. Mostly all of them have worked in their position at the same company for an average of 5-20 years 


\section{Which Social Media tool do you use on a daily basis?}

There is a diverse range of people using different social media tools on a daily basis for their common use. From the replies, Facebook, Youtube and LinkedIn tied at 32.6\% of the total respondents as the social media tool used by them on a daily basis. It was followed by Instagram, with $30 \%$ of the responses, then Google+ with $28.3 \%$ of the responses and lastly Twitter with just $19.6 \%$. WebEx and Whatsapp were also 2 tools that were specially mentioned in the "others" section by some of the respondents.

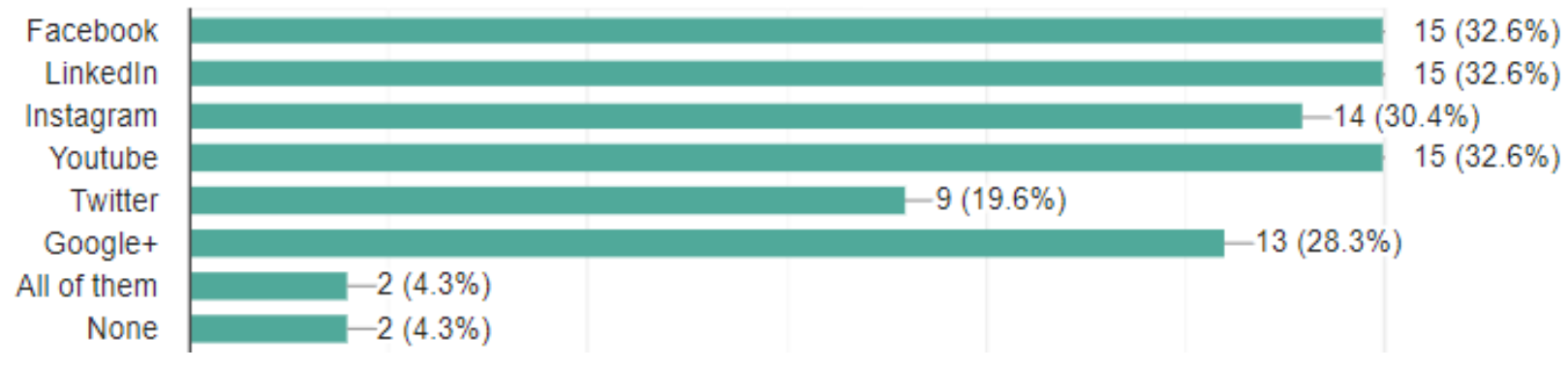

While the rest voted for "others".

How much does this tool improve your work on a scale of 1-10?

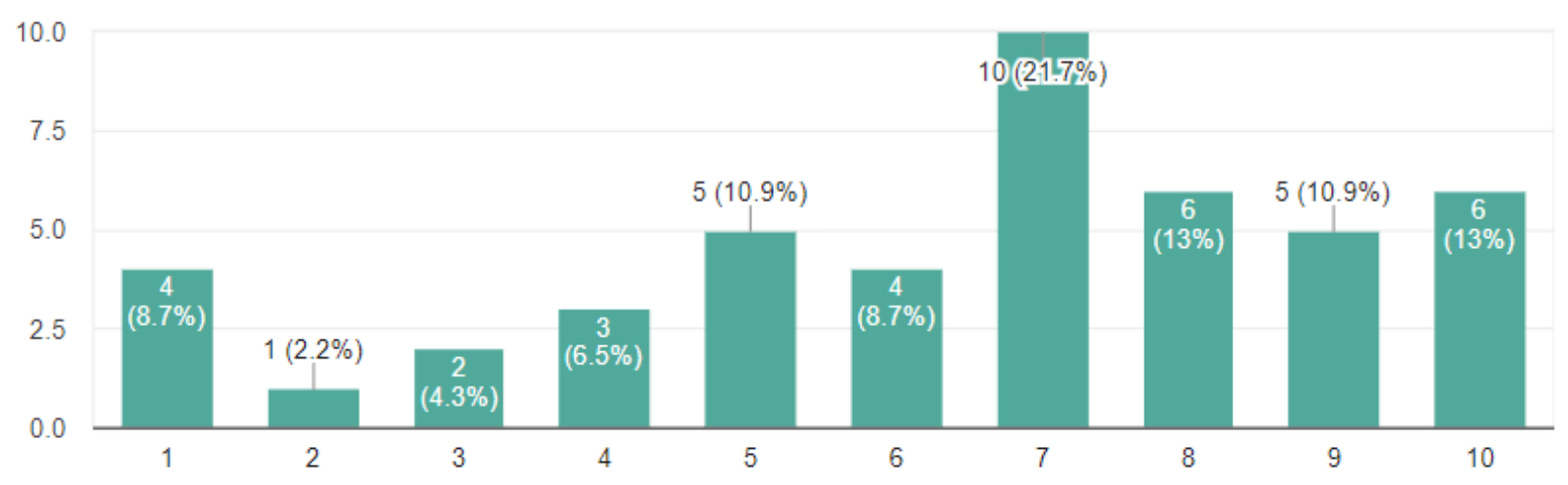

On the topic of how much the social media tool improves their work on a scale of 1-10, the majority of the people responded with 7 (21.7\%), which is above average. 13\% of the people also responded with 10 implying the social media tool significantly improved their work, however a minority of the respondents $(8.7 \%)$ voted for 1 implying it doesn't improve their work at all.

To which business capabilities do you believe Social media contribute most? 


\section{International Journal of Social Science and Economic Research}

ISSN: $2455-8834$

Volume:06, Issue:06 "June 2021"

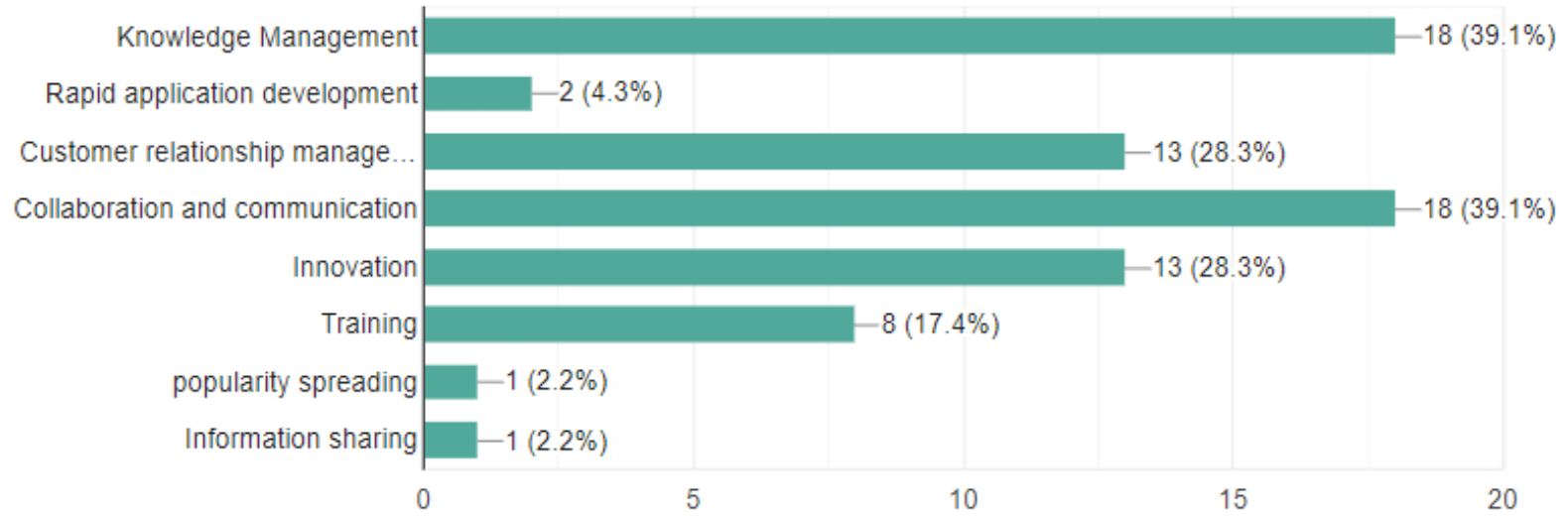

Collaboration and Communication and Knowledge Management were 2 business capabilities that tied and compromised $38.9 \%$ of the votes as the capability the respondents believe social media contributes the most to. Least amount of votes (4.3\%) were given to Rapid Application development,

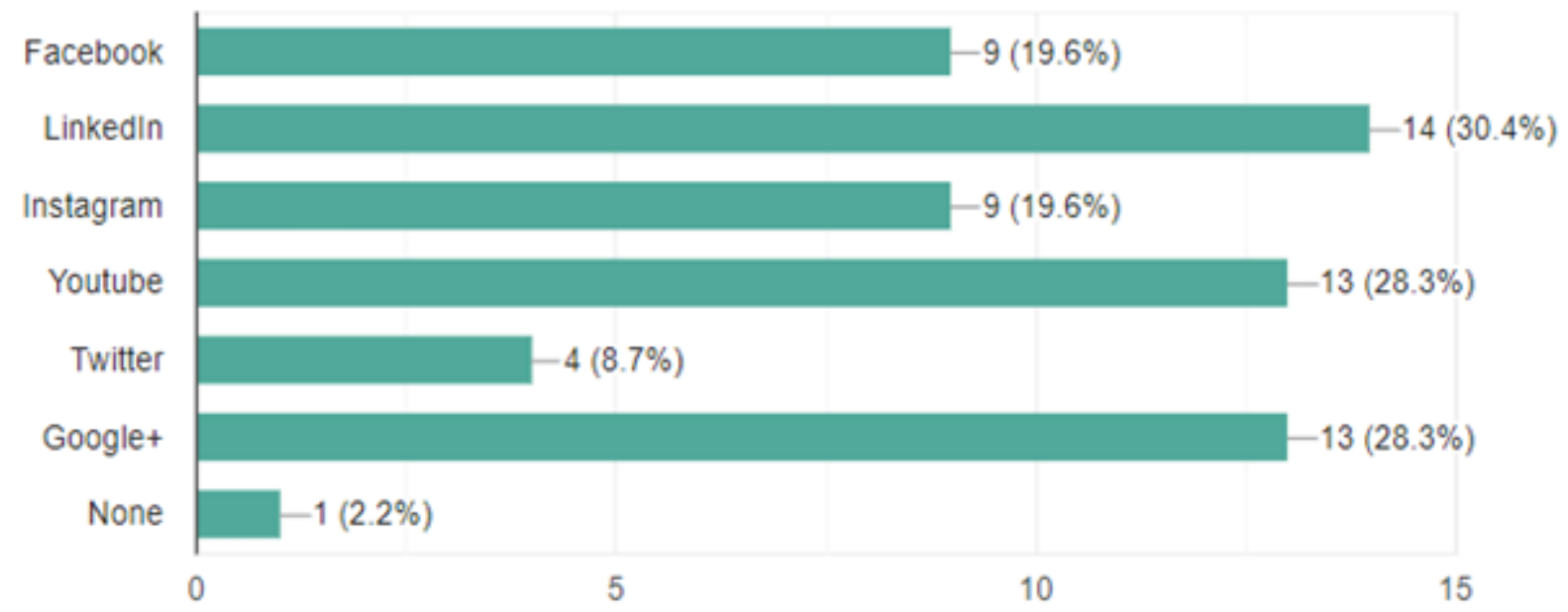

When the social media that contributes the most to all specific business capabilities was asked, maximum votes for Knowledge Management were given to LinkedIn (30.4\%), followed by YouTube and Google+ with $28.3 \%$. 


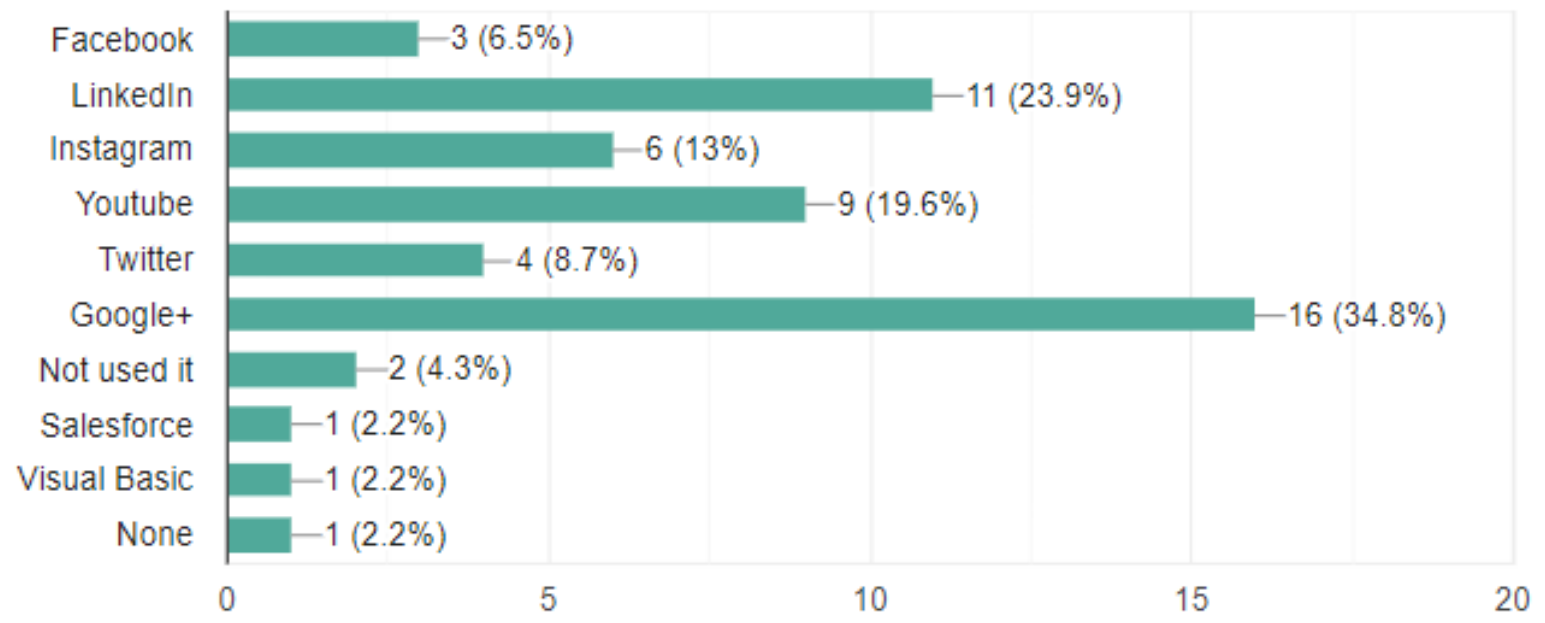

In the case of Rapid Application Development, Google+ was given the most votes (34.8\%) followed by LinkedIn (23.9\%). However, in the others section we saw 2 more social media tools namely Salesforce and Visual Basic which aids in Rapid Application Development for various business enterprises.

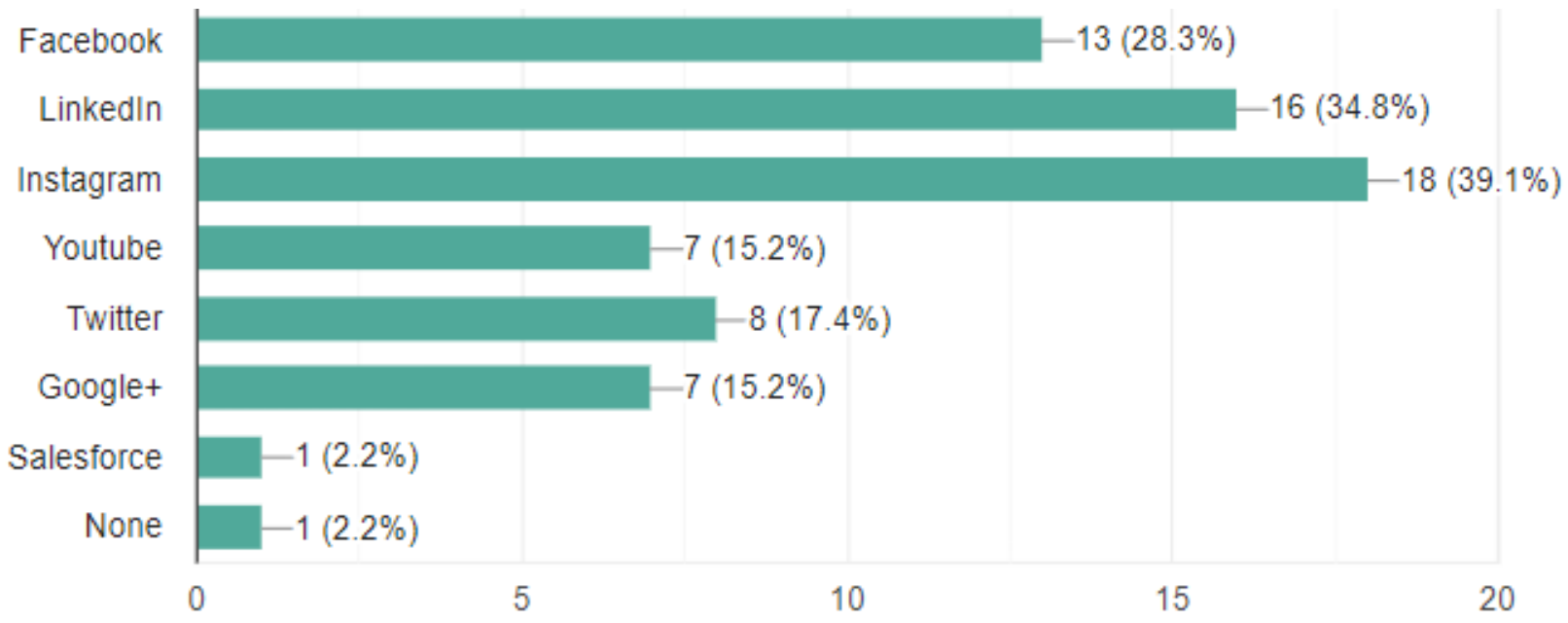

In Customer Relationship Management, 39.1\% of votes were given to instagram, 34.8\% to LinkedIn and $28.3 \%$ to Facebook. As previously mentioned, Salesforce was also submitted as a response for contributing to customer relationships. 
International Journal of Social Science and Economic Research

ISSN: 2455-8834

Volume:06, Issue:06 "June 2021"

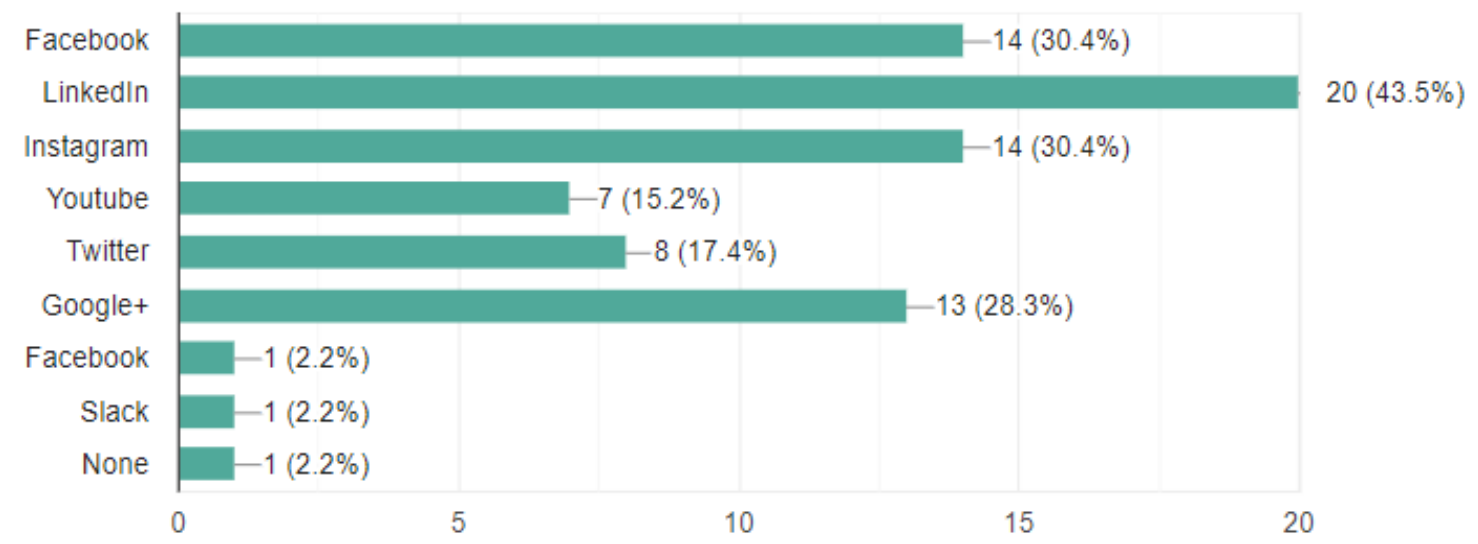

Next up was Collaboration and Communication where maximum votes were given to LinkedIn (43.5\%) followed by Facebook and Instagram at 30.4\%. A new social media tool "Slack" was also mentioned under this capability.

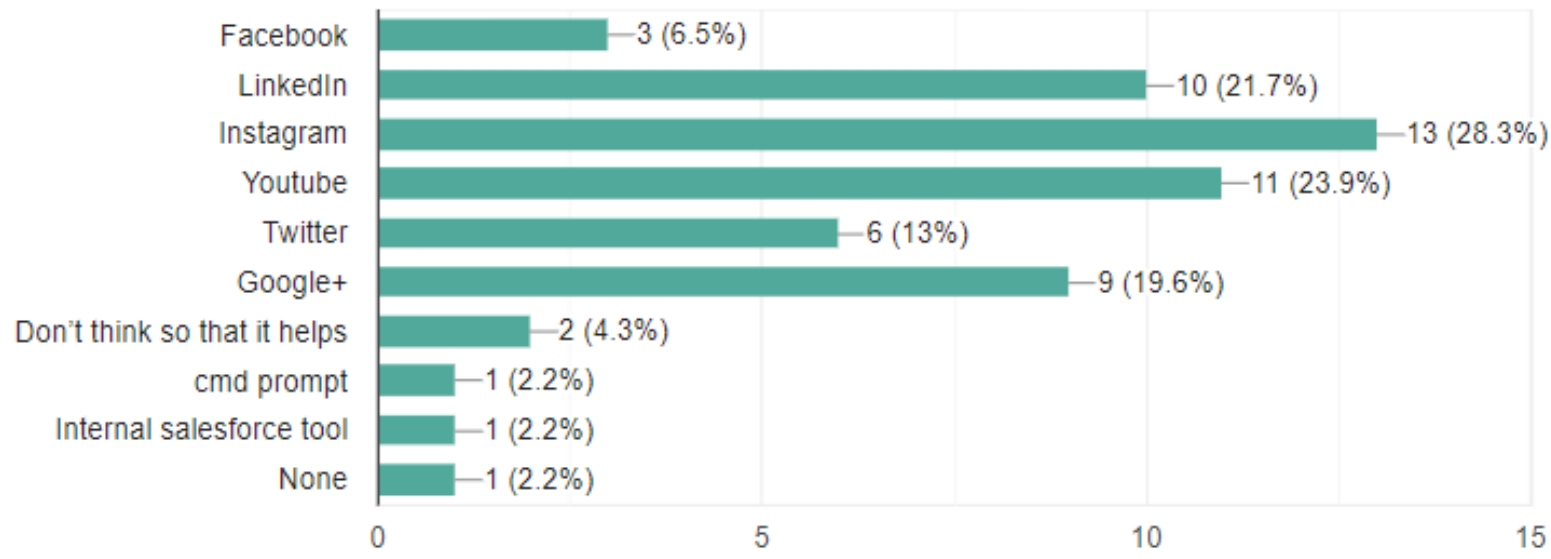

Under Innovation, with $28.3 \%$, Instagram was given the most votes followed by $23.9 \%$ for Youtube and $21.7 \%$ for LinkedIn. Two new entries included Salesforce and cmd prompt. 


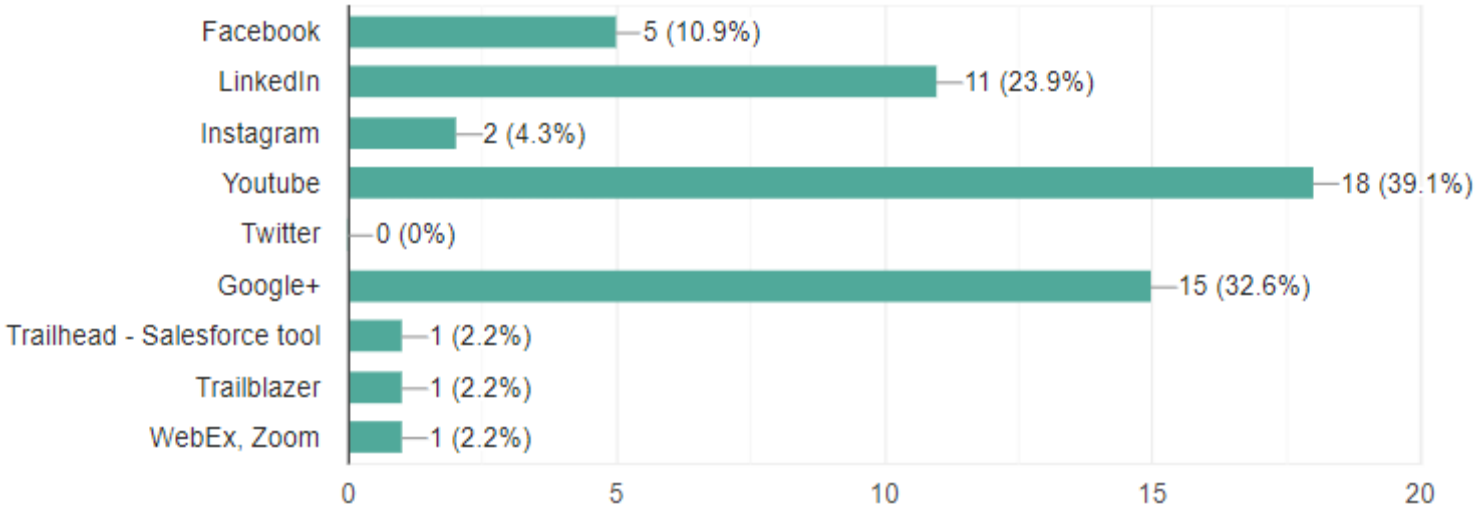

And lastly, for Training, Youtube got the majority of 39.15 of votes followed by Google+ with $32.8 \%$. Trailblazer, trailhead, and WebEX were 3 more social media tools mentioned here to aid with training. The remaining percentage for all of the business capabilities were spread across unequally among the rest of the social media platforms.

How satisfied are you with using Social Media tools in your company?

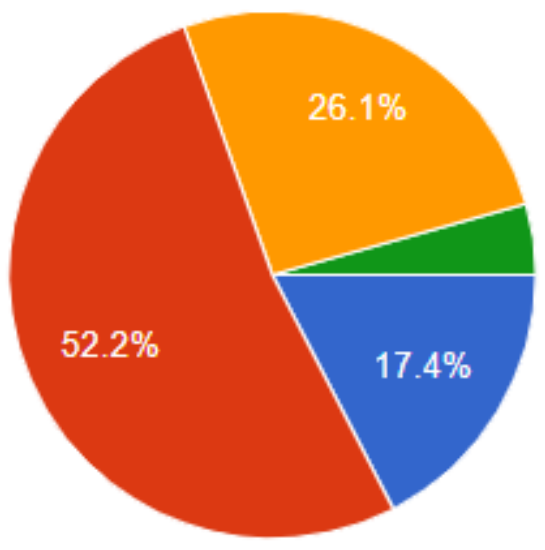

Very satisfied

Satisfied

Neutral

Dissatisfied

Very dissatisfied

In the third section of the survey $52 \%$ of the respondents were satisfied with using social media tools in their company. $26.1 \%$ were Neutral and $17 \%$ were very satisfied with the social media tools. The short remaining percentage of people were dissatisfied but it was negligible as compared to the rest of the responses.

Rate how much your work has improved or has become more difficult since the introduction of Social media? 


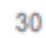

0

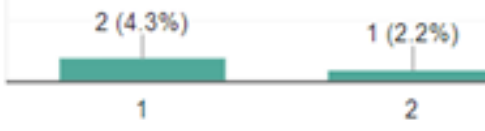

On a scale of 1-5 on how much social media tools have improved their work, $23.9 \%$ voted 5 and $45.7 \%$ voted 4 , so about $70 \%$ of people believe the tools have improved their work significantly. $23.9 \%$ were midway with 3 and the remaining percentage believed that the social media tools did not improve their work, however it was a very small percentage, less than $7 \%$.

How satisfied are you with receiving information from other customers about your company on social media?

30

20

\section{$23(50 \%)$}

10

\section{$10(21.7 \%)$}
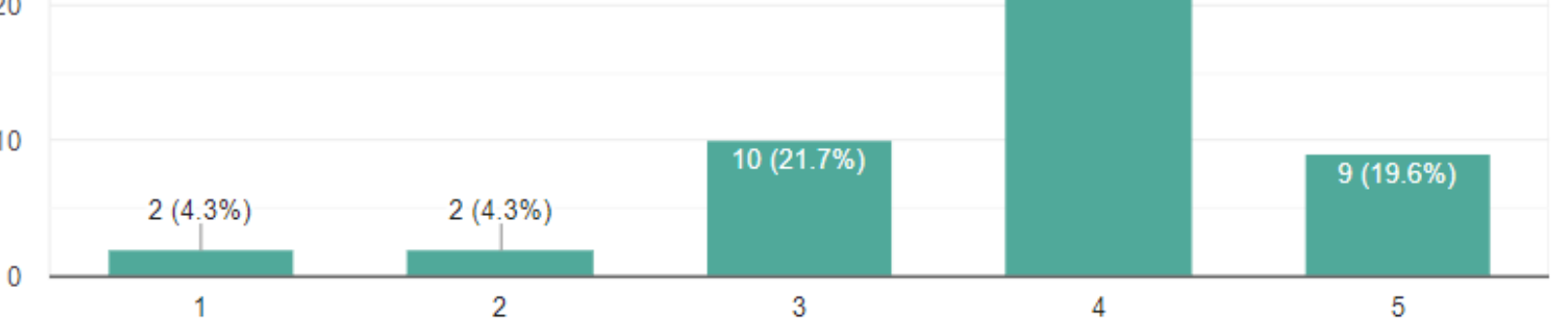

Exactly $50 \%$ of the respondents voted 4 on the scale of $1-5$ as to how satisfied they were with the information received about their company through social media, moreover $19.1 \%$ also voted a perfect $5.21 .7 \%$ were neutral while $8.6 \%$ are dissatisfied with the information.

Compared to other sources, do you believe the received information in social media about the company is the most acceptable or efficient? 


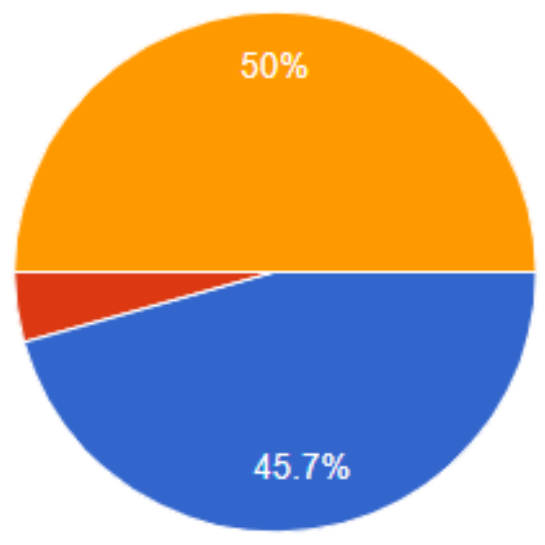

Yes

No

Maybe

$45.7 \%$ of the respondents believe the received information in social media about the company is the most acceptable or efficient, and $50 \%$ of them aren't sure and have voted "maybe". Only $4.3 \%$ think that the information received is not the most acceptable or efficient.

\section{What's one challenge social media has caused you in your work?}

Cost, Increased competition, Making work more competitive in the challenging market. Negative reviews, People expectations, waste of time due to distraction, The drama, Expectations of consumers and employees, not being the lost inclusive, lack of Motivation, Continuous changes of products, Increased Time consumption, ingenuity of information, Plagiarism and exposure to all information to the public domain were the major challenges faced by employees those surveyed.

\section{What's one major advantage that you believe you got through social media?}

Reach /Awareness to CX, Fast communication, Transparency, Visibility, updation of new techniques of doing the same work in a shorter span of time, Ease in getting connected with people, Speed of information, Increase in popularity, Feedback, Knowledge and motivation, Strong communication, Collaboration, Professional Networking and PR, Exploration, and Scope were the major advantages the surveyed employees feel have been achieved through social media.

Would you like to continue watching your company use social media for various operations? 


\section{International Journal of Social Science and Economic Research}

ISSN: 2455-8834

Volume:06, Issue:06 "June 2021"

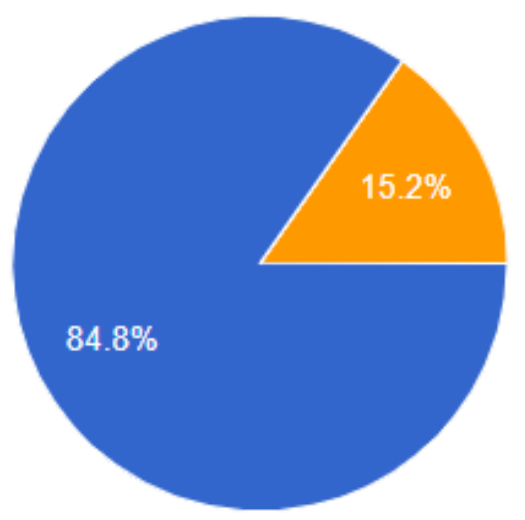

Yes

No

Maybe

Due to the above mentioned advantages, $84.8 \%$ of the respondents want their companies to continue using social media and for the remaining $15.2 \%$, they have voted "maybe" for the same.

\section{DISCUSSION}

There were a large number of respondents from the corporate sectors working in corporations both nationally and internationally in various departments. Some having worked in their position for as little as 5 years and some with 35+ years experience. All in all, there was a diverse group of people that took the survey and a combined consensus is deliberated below.

On the first question, where the social media tool used by the respondents the most on a daily basis was inquired, Facebook, LinkedIn and Youtube all 3 of them tied with $32.6 \%$ of the total votes. Social means simply the interaction among individuals of common interest, a group, or even a community, in this context. And media as its name implies is the media on which the user generated content can be created and exchanged. Social media are in existence for less than two decades, but have become widely accepted. As mentioned in Icha Oyza (2015)

Linkedin was launched in 2003 and Myspace and Facebook followed in 2004. In 2004. Because of Facebook features, social circles have received greater acceptance than others. Youtube started in 2005, followed by Twitter and Blogging, Google+, Instagram, Pinterest, Podcasting etc. In just over ten years, all these have gained over a billion users across the world. It can be clearly seen that these 3 social media have had the maximum impact on the population and hence the results convey the right idea of them being used by the respondents on a daily basis. In the others column, people also responded with researchgate and cisco webex as they weren't available options. Formerly known as Cisco Quad, the technology was integrated into WebEx to create WebEx Social, an environment that encompasses WebEx's virtual meeting capabilities, as well as Microsoft Office integration in group document cooperation, e-mail, mobile and videoappointments. During the times of the pandemic, it has become extremely popular. Not exactly 


\section{International Journal of Social Science and Economic Research}

ISSN: $2455-8834$

Volume:06, Issue:06 "June 2021"

social media, but a social networking platform, ResearchGate has helped millions of students and researchers to achieve their goals and is also becoming popular by the passing of the days.

Next question revolved around the topic of how much the social media tool improved their work. $78.2 \%$ of the respondents voted $5+$ on a scale of $1-10$, among which $13 \%$ voted 10 implying that it improves their work significantly. The efficacy of social media services in information sharing, creating, exchanging and interactive communication has resulted in a wide range of use of social media services across the various fields to improve the efficiency of related activities in particular sectors. For example, while social media services are discussed as having a negative impact on learning processes, teaching - if used appropriately - is also too effective. Due to interactive media and communication functions, social media services participate actively in different management fields. One is also the business area, which is popular among today's companies with the usage of social media services as "social media marketing tools." Trattner and Kappe (2013) define the concept of social media as being able to receive traffic or attention - popularity via social media services. In brief, social media services are used to commercialise companies' related works. By assessing the advantages of social media, an exact mechanism for corporate works can be better understood. However, just like any other thing, social media also has its share of disadvantages, however they are minimal when compared to how much the tool is. These disadvantages are the reason why $27.8 \%$ of the people have voted below 5 on the scale, with about $8 \%$ voting on " 1 " implying that the social media tool they use on a daily basis does not improve their work at all, and rather causes trouble.

Digital media has given consumers and employees the power and authority to make business changes. This shift has brought about a dramatic change in the role of planning and evaluating the trend without the consumer market (Kim \& Ko, 2012). It is important to analyse the myth related to the internet media in order to understand the role of social media in today's business environment. The Internet has traditionally been regarded as a predominantly unlimited platform through which firms can provide consumers and employees with a lot of information. The following question focused on some business capabilities the social media contributed the most to. These included Knowledge Management, Innovation, Training, Rapid Application Development, Collaboration and Communication, Customer Relationship Management and Others. Knowledge Management and Collaboration and Communication received the most votes and both of them tied at $39.1 \%$ of the total votes, which implies that social media has contributed the most to these fields of business management. Following this was customer relationship management and Innovation which also got tied at $28.3 \%$ of the total votes. Training, and Rapid Application development followed $17.4 \%$ and $4.3 \%$ of the total votes respectively.

Next up, one by one, all the business capabilities were taken up and assessed on the basis of which social media contributes most to that respective business management capability. 


\section{International Journal of Social Science and Economic Research}

ISSN: $2455-8834$

Volume:06, Issue:06 "June 2021"

Knowledge management is a conscious process in which employees' knowledge and experience in an organisation are defined, structured, preserved and shared. The main objective of knowledge management is to improve efficiency of an organisation and save company knowledge. It often refers to training and education in a company or its clients. It consists of a cycle of knowledge development, communication, structuring and auditing to maximise the efficiency of collective knowledge within an organisation. The objective is to facilitate organisational education and create a culture of learning that promotes the sharing of knowledge and facilitates the learners who try to improve their skills. It is helpful to consider its types and how it can be shared in an organisation when thinking of knowledge management. The two main types of knowledge covered by the definition of knowledge management are silent knowledge and explicit knowledge. Tacit knowledge is intuitive, easier to package and share. Innovative thinking and understanding of body language are examples of tacit knowledge. Explicit knowledge is easily codified and taught information such as how the toner can be changed in printer and mathematical equations.

Successful management of knowledge will improve an organisation in various ways. It ensures that employees' specialist knowledge does not leave or go unused by other employees that benefit from this knowledge. It allows for a greater awareness of the situation and opens doors for knowledge of good practises, learning and overall improvement in the organisation. The knowledge management (KM) is now in high growth, mainly in the business industries, as Dr. A Arun Kumar (2015) says. Because early adopters' performance metrics document the significant benefits of knowledge management, more organisations recognise the value of leveraging corporate knowledge. $\mathrm{KM}$ is now promoted as important and necessary components for organisations to survive and maintain competitiveness and their related Strategy Concepts.

As per the responses, LinkedIn contributes most to Knowledge Management as it captured $30.9 \%$ of the total votes which was the majority. It was followed by YouTube and Google+ which tied at $28.3 \%$ of the total votes, hence, also contributing majorly to this management capability. Kaplan and Haenlein (2010) maintain that social media users deliberately or inadvertently disclose themselves or their behaviour information and therefore implement a strategy of self-promotion or self-branding in order to improve visibility. Kietzmann et al. regards social media as a channel of reputation, through which a company or staff potential can be presented as reputation. Social Media generates content that can be used irrespective of the time it is created, usually as heritage knowledge, by means of various clients' activities. Therefore, Social Media is recognised by Danis and Singer as an IT resource, where users consciously disclose information on current projects and skills of those involved in such projects, all of which can serve as knowledge for future uses. Social media by contrast, is also treated as panels where situational activities and the accompanying discussions are monitored. LinkedIn 


\section{International Journal of Social Science and Economic Research}

ISSN: $2455-8834$

Volume:06, Issue:06 "June 2021"

having features enabling these functions is the reason why the majority of the respondents chose it for contributing the most to Knowledge Management, however, it is very clear that all kinds of Social Media contributes largely to this capability of a business.

The rapid development of application is a type of Agile development model, which was introduced in the 1980s. The invention was the result of the inconveniences of regressive traditional development models like the Waterfall development software model. One of the biggest flaws in the waterfall model was that it is difficult to change its central functions and features once the software has entered the testing phase. In the end, one ends up with a software which might or might not meet your evolving needs. RAD was to challenge this for the first time. In short, RAD allows the rapid development of low-code applications that allow business to deploy new apps more quickly. As you might have known, even if the model has long been discovered, it is important in today's competitive marketplace, where technology changes at much faster speed than ever before! The 2018 digital transformation hour's call is RAD.

It is required as it provides Quick, constant user feedback.There is nothing more valuable in software development for a developer than receiving relevant user feedback. With recurring iterations and prototype releases the RAD method allows for almost continuous feedback, giving the entire team a valuable assessment and a criticism at the right time.

It provides a Quantifiable progress. The progress of total projects as well as the independent components can be easily measured because of frequent iterations, components and prototypes. Adjustments can be made to keep schedules and budgets wherever necessary.

Software Components Separation is another benefit. RAD is advantageous by obliging designers and developers to create components independently from each other, as with object-oriented software conception procedures, in which components are quarantined. In RAD, each element of the software is partitioned and thus modified independently as the software needs develop.

There is an Easy adaptability. Software is in a mixable form during RAD development. This means code can be changed to alter or generate new components dramatically throughout the software system. The development team should take advantage of this flexibility early on to finally develop immaculate software through iteration and prototyping of potential ideas and concepts.

Lastly it Quickly generates Productive Code. A large proportion of active developers of software quickly improve their abilities and become multidisciplinary, such as full-stack developers. RAD helps developers' teams produce prototypes quickly and works with code to show examples that might take months otherwise to see daylight. Due to these, it is very important for business management. 


\section{International Journal of Social Science and Economic Research}

ISSN: $2455-8834$

Volume:06, Issue:06 "June 2021"

Google+, a Google operated social media was the most voted by the people who took the survey as the social media tool that contributes most to this management capability. It is followed by LinkedIn with $23.9 \%$ of the total votes. The demand for business applications has reached an unprecedented level as the world migrates to the mobile, social media and the cloud. However, an HBR study suggests that over 200 percent of one out of six projects costs overcrowded budgets. During the periods, about 70 percent are overtaken. In addition, over three-fourths of the companies failed in their efforts. These statistics only demonstrate the importance that SMEs as well as large-scale organisations have a rapid application development platform. The hour is needed to invest in a RAD platform to reduce friction in the delivery of apps and the work of companies that they now experience. Practically, social media does NOT directly help in this business capability except giving the right information needed for it to take place. Applications like Salesforce and Visual Basic, which are not exactly social media was answered by the respondents under the "others" section which supports our conclusion for the same.

Management of Customer Relations (CRM) combines practises, strategies and technologies used by companies in the management and analysis of customer interactions and data during the entire customer life cycle. The aim is to improve customer service and support customer retention and growth in sales. CRM systems compile the customer data between the customer and the company on various channels or contact points that may include a web site, telephone, live chat, direct mail, marketing and social networking materials for the company. CRM systems can be used by organisations from small enterprises to large companies Customer support representatives are able to easily access information such as past purchases and interaction history, providing improved and rapid customer service, Collecting and accessing customer data can help businesses identify customer trends and insights by reporting and displaying features and automating the menial yet required sales funnel and customer support tasks. CRM helps companies make sense of customer needs, manage these relationships more intelligently and help predict the future (Dominici and Guzzo, 2010).

Kho (2008) claims that many similar objectives as b2c in terms of SCRM are pursued by b2b companies. SM cultivates substantial interactions between the company and its customers for CRM purposes. The focus and the responsiveness to customer concerns enable companies to intensify customer dialogue and resolve customer concerns, thus improving customer satisfaction and loyalty. Michaelidou et al. (2011) found that fostering customer relations for b2b-based companies using SNS is a crucial objective. In this regard, Bodnar and Cohen, from the use of SM as a branding tool (2012), provide a new perspective in which SM generates sales and helps customers through the purchasing cycle. In accordance with Schultz et al. (2012), a good correlation has been identified between SM use and sales performance that means that SM is a 


\section{International Journal of Social Science and Economic Research}

ISSN: $2455-8834$

Volume:06, Issue:06 "June 2021"

sales tool that is strategically and operationally useful. SCRM recognition offers important insights into the b2b marketplace.

According to the survey, Instagram contributes most to Customer relationship management as it received $39.1 \%$ of the total votes, followed by LinkedIn and Facebook with $34.8 \%$ and $24.3 \%$ of the total votes respectively. Social media at CRM involves companies with customers, such as Facebook, INstagram and LinkedIn, directly via social media platforms. Social media presents an open forum for customers to share experiences with a brand, be it complaints or product promotion. Companies use various social CRM tools for monitoring social media conversations - from specific brand mentions to keyword frequencies, to determine the target audience and what platforms they use, to enhance customer interactions in social media. Additional tools are designed to analyse feedback from social media and address customer queries and problems.

Companies are interested in acquiring customer feelings such as the probability that they will recommend products to market and service strategies, and their overall customer satisfaction. Companies try to include social CRM data from sales or marketing departments with other customer data to obtain an entirely unique view of the customer. Another way in which social CRM creates added value for companies and customers is by providing customers with product reviews and in time for problem-solving and/or research products with other customers. For certain types of problems, customer communities can provide low-level customer service to reduce the number of contact points. Customer groups can also provide new product ideas or feedback that companies can take advantage of instead of feedback groups. Therefore, as analyzed from the survey responses, these social media tools contribute immensely to this business management capability.

Next up was Collaboration and Communication. Communication allows relationships to operate and their functioning allows not only cooperation to be productive but also to take place. This realisation allows business IT departments to begin to understand that they can increase their productivity and further the success of their business by using technology - especially unified communications technology. Unified communications are not some futuristic devices from 2001; a space odyssey, but more than just a product, providing a consistent and unified user experience across several devices, platforms and media types. Unified communication is not a product. This includes communication services like instant messaging, chatting, voice, web \& video conferencing, desktop sharing, data sharing, call control, fixed-mobile conversation and voice recognition with non-real-time communication services like single messaging. communication services are also included (integrated voicemail, e-mail, texting, and fax).Over the past decade, business has truly changed. Driven by technological opportunities, people like them in their personal lives want to communicate and collaborate more. Gartner forecasts the use of social networks to be more than 1.5 billion by 2016. Marketers have an enormous chance. 


\section{International Journal of Social Science and Economic Research}

ISSN: $2455-8834$

Volume:06, Issue:06 "June 2021"

Communication and collaboration is faster, easier and much more natural than before the emergence of modern tools for collaboration. However, it is not only for clients. They are also more involved and more productive in a virtuous cycle when employees are socially connected.

The way people communicate with one another has changed radically with social media platforms like Facebook and MySpace. Social networking websites, once considered to be tools for young people, are now the main communication tools for people of all ages. In fact, social networking sites are the primary means of online communication, overtaking email in the previous few years. ComScore, the leading Internet traffic measurement organisation, has reported that social networking communication exceeded email communication for the first time in 2009. (Hinchcliffe \& Kim, 2012).

LinkedIn once again was voted as the biggest contributor to Collaboration and Communication with $43.5 \%$ of the votes followed by Instagram and Facebook, both tied at $30.4 \%$ of the total votes. Peter Cardon [2014] also suggests that Enterprise social networking platforms may emerge as the primary form of business communication. The reasons for dragging their feet are rapidly decreasing for companies that have not yet experienced Corporate Social Media power. Social media has been used enormously by the public. Customers interact, create profound links and communicate more often with favourite brands. This provides more insight into connected companies, allowing them to create yet richer interactions, and to improve communication, products and services. Social CRM enables an organisation, through social channels such as LinkedIn, Instagram and Facebook, to start to engage its customers and prospects in collaboration. Businesses can learn more about their customers' preferences and dislikes by incorporating social media into sales, marketing and customer service. By leveraging available information, they can discover more leads with greater personalisation and speed to improve the overall customer experience.

The dictionary only refers to "the introduction of something new" to innovation. This is not just about inventing something different, like a product, because it must also be introduced and launched into the world. "Innovation Management" therefore refers to managing all the activities required to "introduce something new." That is to say, in practise, ideas are produced, developed, prioritised and implemented, and implemented, for example through the launch of new products or the introduction of new internal processes. It is easy to demystify the term by just looking at the definition. Management of innovation is simply the process of bringing new things forward and developing the business, one way or another. The innovation process is defined as the development and selection of ideas for innovation and the transformation of these ideas into innovation (Jacobs and Snijders 2008). To emphasise the uncertain character of this innovation process, other authors use the innovation journey (Van der Ven 1999). An innovation project is in this paper used as being the innovation process of one particular innovation. Andrew and 


\section{International Journal of Social Science and Economic Research}

ISSN: $2455-8834$

Volume:06, Issue:06 "June 2021"

Sirkin (2006) argue that the management of an innovation project is essentially like any other business projects, though it comes with more risk and uncertainty. What makes this interesting is the lifecycle of an innovation. Whether they are progressive or disruptive, each innovation undergoes several very similar phases in its lifecycle. Search - Build - Scale - Expansion Sustainability. These phases cover all from innovation from a simple idea to construction, marketing and building a company out of it and then sustaining it as long as it becomes meaningful.

As per the survey responses, $28.3 \%$ of the total respondents believe that social media tools like Instagram contribute mostly to this category followed by $23.9 \%$ people for Youtube and $21.7 \%$ of the total votes for LinkedIn. SM was also described as an ideal tool for internal management innovation (Laroche, Habibi, Richard, 2013). Employees could broaden their internal contacts and improve conventional workplace communications, thus improving knowledge and experience integration. This theoretical aspect is supported by empirical models. Use of information from SM sources for New Product Development can increase project-level innovation performance, but only under specific conditions for some types of innovation. Some key individuals can use the SM without the formal mandate of their superiors and show their personal curiosity and engage in the application of the SM. However, their ability to engage in this kind of activity is a reflection of their organization's innovation culture. A willingness to experiment, a tolerance of mistakes, and the ability to learn are all aspects of such a culture (Terziovski,2010). In unison, a strong innovation culture also prevents "not invented here"syndrome, i.e., guarantees that the external information acquired via SM is also utilized for NPD. Due to which reason, one of the respondents has also mentioned that they don't think social media helps in Innovation while others have suggested applications like SalesForce and CMD prompt which don't necessarily fall under this category. Nonetheless, as the time goes by, SM will be a major contributor to Innovation Business Management as stated in the research paper by Deborah L Roberts [2016].

Lastly, Management Training is a training activity, which aims to improve a person's skills as a leader and manager. Soft skills such as communication and empathy may be emphasised, which allow for better teamwork and more progressive relations with the people they manage. Leadership skills, such as the development of a progressive style to involve employees, may also be an area where leadership training is probably known. Management training can also be centred on the business side, such as reporting to senior leaders, leading performance reviews and acquisition of talent (where responsibility for recruitment falls with managers). Any company's employees are the principal assets. To perform the work efficiently and effectively, all companies need well-trained staff. The ongoing process of the organisations contributes to the development of skills, knowledge and skills. The better performance of employees is led by 


\section{International Journal of Social Science and Economic Research}

ISSN: $2455-8834$

Volume:06, Issue:06 "June 2021"

training and development. The company's success depends on the performance of its staff. Training is crucial for the skilled and challenging business in this era of globalisation. It is the nerve that needs to help improve employee quality and the organization's development. Training and development in most organisations are crucial factors to enhance employee performance. Mobarak Karim (2019).

Social media has allowed corporate learners to evolve to active contributors from passive knowledge consumers. As technology progresses and mobile devices proliferate, social media has expanded the opportunity of corporate training, as never before. Top social media sites such as Facebook, Twitter and LinkedIn bring your dispersed employees together and provide them with an increased range of learning opportunities! $39.1 \%$ of the total votes went to Youtube implying it contributes most to Training management followed by $32.6 \%$ votes for Google+ and $23.9 \%$ of the total votes for LinkedIn, making them both significant contributors to training. Grovo Learn, Inc. has identified Facebook as the most popular social media site among enterprises for enterprise training, and LinkedIn and Twitter as the most rapidly-growing education platforms with growth of $349 \%$ and $226 \%$, supporting our findings.

SMEs can help employees address their immediate concerns and needs as specialists with extensive knowledge and experience in the domain. The use of social media as an open channel helps one create a good working relationship between small and medium-sized enterprises and learners. onecan invite your staff to ask questions about the SME in a just-in-time context, whether oneare using a LinkedIn group, Facebook, a custom wiki or a designated Twitter hachage. SMEs can also use such platforms to provide employees with ongoing clarifications or updates. With social media platforms, employees can also look at the programme in reality through an on-the-job experience of a SME. If an ILT with demographically scattered employees provides corporate training, social platforms such as Skype could be most meaningful.. Unlimited choices are available. TrailBlazer, WebX, Zoom, and other such applications have also been put as responses which don't exactly come under social media tools.

Social media has an effective and outstanding role in today's marketing approaches. It can be said that the popularity of social media services in especially marketing activities has great potential for the future due to continuing rapid improvements in computers and communicationsrelated technologies. This paper explains some recent, notable success stories in social media marketing, which are examples for understanding the impact of social media in corporate projects and assessing the key success stories for improving the company from different perspectives. Of course, many different examples of social media marketing applications can be focused on, but this makes it evident why $52.4 \%$ of the total respondents are satisfied by the role of social media. $91.3 \%$ of the total respondents also voted $3+$ on a scale of $1-5$ on how much they're satisfied with social media tools, implying it's clearly satisfactory. 


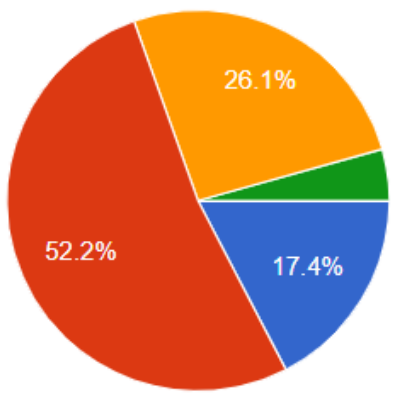

Fig i

Fig $i$ is the graphical representation of survey responses for the question inquiring how satisfied they are with the use of social media by their corporation. Substantial changes to communication entre organisations, communautés and individuals occur in social media. social media This presents a huge challenge for companies, as many well established management methodologies are unsuitable for dealing with customers who no longer want to talk about them. Companies that want to take social media seriously will find in the honeycomb framework a useful tool. By analysing the seven building blocks - identity, conversation, sharing, presence, relationships, reputation and groups - companies are monitoring and understanding the ways in which social media activities vary with respect to the way they function and influence, as stated by Jan Kietzman (2011).

The next question in the survey focused on the respondents beliefs and if they believed information received about their business through social media was the most acceptable or efficient. Below are the results, with $50 \%$ maybe and $45.7 \%$ yes, leaving only $5 \%>$ for no.
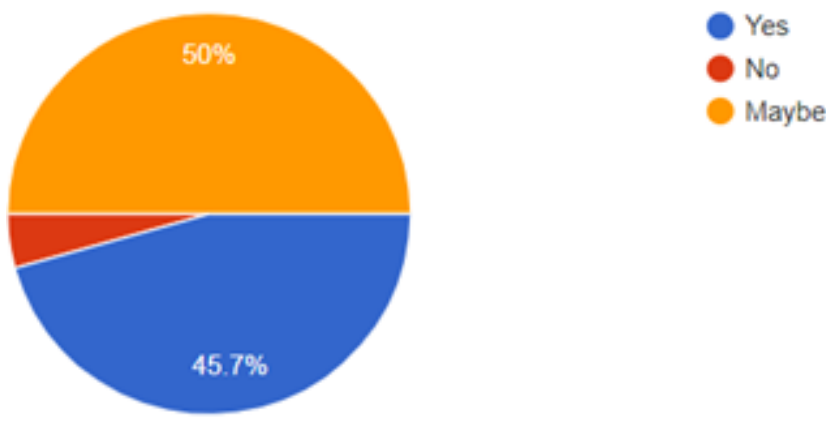


\section{International Journal of Social Science and Economic Research}

ISSN: $2455-8834$

Volume:06, Issue:06 "June 2021"

Today the Internet is by itself one of the ways that organisations have found connections with their consumers is through social media, the fastest way to gain consumer attention and a wide reach. Social media websites such as Facebook, Twitter, Google+ and Pinterest provide companies with an immense opportunity to take care of customers while creating a brand image at the same time. Companies have learned how to use social media websites as a step in building brand awareness or campaigning for consumers.

Social media platforms offer the perfect occasion to exploit word of mouth and witness its diffusion. In developing countries, social media is growing at its fastest rate. People are connected globally and by online observation participate casually in the lives of each other. "Liking" a brand can spread virtually fast on the different social media channels on Facebook. Kietzmann (2013) emphasised that consumers are more comfortable with their peers' opinions than paid company advertising.

Corporate, marketing and how organisations deal with their target market played a big influence on social media. Therefore, it would be useful for any business to develop and implement a sustainable social media strategy in order to take advantage of this rapidly changing environment successfully. The use of social media is growing. The invention of 'trending issues' is another influence of social media, A trend on Twitter is a hashtag-driven topic which at a given time is immediately popular. Trends are determined by an algorithm which tracks hot subjects based on who you are following and where you are.

Social Bakers provides social media analysis and publishing services to thousands of Facebook, Twitter, Google+, LinkedIn, You Tube, Instagram and VK industries. The company offers deep data analysis for thousands of brands. It allows organisations, in order to increase marketing effectiveness and efficiency, to monitor and optimise the effectiveness of their social media campaigns, to measure their competitiveness and industry standard. The site provides data on the fastest-growing social media presence in accordance with industry, names, brands and entertainment as discussed in Icha Oyza (2015).'

Due to the above factors, the majority percentage of respondents believe that information received through social media tools for their businesses is the most acceptable or efficient.

Two subjective type questions talked about the challenges faced and advantages received since the introduction of social media into businesses. Starting off with the summary of all advantages.

Cost-related is the main benefit of social media marketing. Compared to others, there are very little financial barriers to social media marketing. Most social media websites can be accessed, profiles and postings free of charge. While traditional marketing campaigns can cost millions of dollars, numerous social media tools are also available for commercial applications. Companies 


\section{International Journal of Social Science and Economic Research}

ISSN: $2455-8834$

Volume:06, Issue:06 "June 2021"

can run very successful social media marketing campaigns on a budget that is limited. The advantage is substantial in reaching your target market for little or no cash investment and you will voluntarily be joined or followed by the audience. Weinberg (2009) talks about it being the biggest advantage of social media in businesses hence proving our research.

The increase and the creation of new forms of social interaction is one of the most significant phenomenons of new media. More than a quarter of people spend their time online on communications activities (e.g. emails, IM chat and social media), which corresponds with the total amount of time spent online for general recreation and entertainment quoted by (Hill \& Moran, 2011). Social networking sites are so widespread that they are the most popular destinations on the Internet. It is not only clear how often people communicate online that new media have changed, but also expanded the pool of people they communicate with and lead to new ways to influence behaviours.

Social media enables marketers to target audiences and consumers based on the personal interests of site users and the likes of their friends. One is most likely to see an advertisement on country music concerts and musicians on a social networking site, for example. Advertising on some sites will also highlight the countries friends like to connect with. Marketers effectively reach people who are most concerned about what they offer by means of such "smart" marketing and advertising.

Furthermore, social networking enables word of mouth to promote products beyond what advertising alone does as cited by Hill, Provost \& Volinsky, 2006. This also ensures a global reach which is extremely beneficial.

Efficient customer service can also be achieved through social media and not to forget all the business capabilities it contributes to. Social media is one of the most prominent means of increasing the transparency of brands. The best platform for this personal connection is social media marketing channels. For marketing using social media, transparency is important. The public knows what companies do because of transparency. This will allow customers to start trusting companies to interact with customers and establish relations between customers.

However, there were also lots of challenges mentioned by the respondents as discussed below are some of them.

Social media are interactive and successful, bidirectional, but time-intensive. The nature of marketing changes in social networks, with a focus on long-term relationships, which can lead to greater sales. Someone must monitor every network, answer comments, answer questions and provide customer-worthy product information. Companies without a service will find it difficult 


\section{International Journal of Social Science and Economic Research}

ISSN: $2455-8834$

Volume:06, Issue:06 "June 2021"

to compete for these social networks. The first and probably main consideration is that social media marketing takes a considerable amount of time to invest (Barefoot \& Szabo, 2010).

It is extremely important for companies, Steinman and Hawkins (2010), when using social media to promote their own brands and products, to protect their own trademarks and copyrights. Brands and other intellectual property of a company are often as valuable as their products or services. The ability of social media to promote informal and impromptu communication in realtime can help companies promote their own brands and disseminate copyrighted materials, but can also facilitate the misuse of trademarks and copyrights by third parties. Sometimes it could also lead to plagiarism. This type of business personality may harm the brand and reputation of a company when left unchecked, as stated by Steinman and Hawkins (2010).

Social media channels can also involve trust, privacy and data security problems in promoting one's own brand, products or services. Companies must be aware of these issues and take appropriate measures to minimise their exposure to responsibility for the collection, use and maintenance of personal information. Confidence plays a critical role in generating loyalty to social media marketers, in particular, the unique dimensions of transactional security and privacy. A study by Ratnasingham (1998) demonstrated that anxiety about online bankruptcy is one of the main reasons why clients haven't purchased more extensively online.

In certain ways, social media transforms consumers into marketers and publicity providers, and the consumer can put positive or negative pressure on the company, its products and services, depending on how the company is presented online as well as the quality of products and services submitted to the customer. Product reviews, images and tags generated by consumers that provide valuable information for customers making online product choices have rapidly increased on the Internet and have had an important impact on electronic commerce after the emergence of SM technology. Negative postal responses are a particularly damaging aspect of social networking for marketing campaigns. Disappointing customers or competition in the industry are entitled to post despicable or offensive photos, articles or videos, and a marketer cannot do much to prevent these events. Negative or other feedback cannot be ignored, however. Social networks must be effectively managed to react immediately and neutralise harmful jobs.

Lastly, the survey was concluded by asking if employees would like to continue seeing their business corporations use social media tools. With $84.8 \%$ people in favour and $15.2 \%$ in doubt possibly due to the challenges mentioned above, however, none of them voted no. 

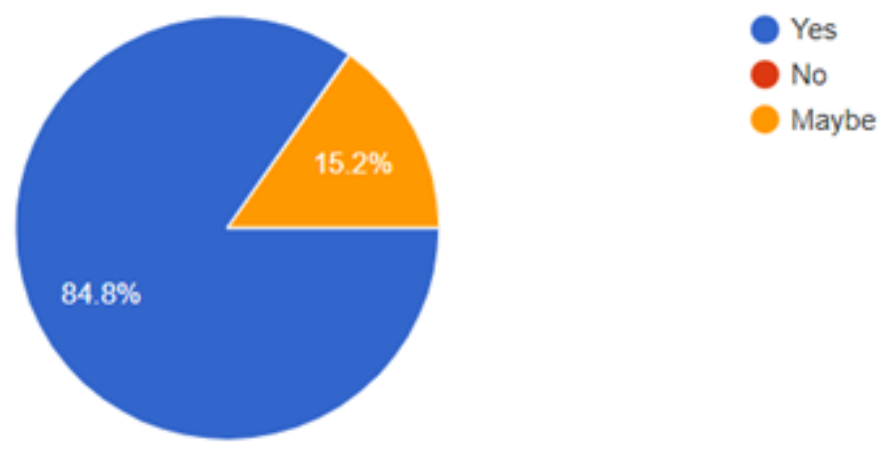

\section{CONCLUSION}

It is therefore fair to conclude that the use of the social media application and tools has been demonstrated to enable enterprises to brand their products more and to reach their brands more customers and better meet their requirements. By using social media companies have experienced an increase in their brand awareness. There are a lot of advantages, but also a few drawbacks, but companies can better use social media by clarifying their own message, avoiding chaos and ensuring their brand image is matched online. Marketers view social media as the goldmine for brands, business development and construction, a space for all of their consumers. It contributes to many management capabilities and is used to the utmost satisfaction of most employees.

\section{REFERENCES}

Khadija Abdipour (2019), The impact of social media in business growth and performance: A scientometrics analysis. Retrieved from https://rb.gy/cp3zpg

Venkateshwaran Radhakrishnan (2019), Impact of Social Media Application in Business Organizations. Retrieved from: https://rb.gy/jyvxij

Kawaljeet Kaur Kapoor (2017), Advances in Social Media Research: Past, Present and Future. Retrieved from: https://link.springer.com/article/10.1007/s10796-017-9810-y

Mohammad Yousef Abuhashesh (2014), Integration of Social Media in Businesses, retrieved from: https://ijbssnet.com/journals/Vol_5_No_8_July_2014/20.pdf

Utku Kose (2014), Impact of Social Media on Marketing: A View on Success Stories, retrieved from: https://rb.gy/ghouzy 
International Journal of Social Science and Economic Research

ISSN: $2455-8834$

Volume:06, Issue:06 "June 2021"

Mohammed Hussein Mama Irbo* and Abdulnasir Abdul Malik Mohammed (2019), Social media, business capabilities and performance: A review of literature, retrieved from: https://academicjournals.org/journal/AJBM/article-full-text-pdf/9BAE2CF64693

Gil Appel (2020), The future of social media in marketing retrieved from: https://link.springer.com/article/10.1007/s11747-019-00695-1

Simeon Edosomwan (2011), The history of social media and its impact on business, retrieved from: https://rb.gy/c6r0zb

Andreas Kaplan (2010) Users of the World, Unite! The Challenges and Opportunities of Social Media, retrieved from: https://rb.gy/foryeo

Jan Kietzman (2011), Social Media? Get Serious! Understanding the Functional Building Blocks of Social Media, retrieved from: https://rb.gy/cnnhgn

Gaurav Seth (2012), Analyzing the Effects of Social Media on the Hospitality Industry, retrieved from:https://digitalscholarship.unlv.edu/cgi/viewcontent.cgi?article=2338\&context=thesesdissert ations

Efthymios Constantinides (2014), Foundations of Social Media Marketing, retrieved from: https://rb.gy/ndy3cq

Nina Eyrich (2008), PR practitioners' use of social media tools and communication Technology, retrieved from: http://www.kayesweetser.com/wp-content/uploads/2007/04/eyrich-et-al-2008-prpractitioners-use-of-social-media.pdf

Martin Smith (2013), impact of social media on business performance, retrieved from: https://aisel.aisnet.org/cgi/viewcontent.cgi?article=1348\&context=ecis2013_cr

Rajiv Kaushik (2012), Impact of Social Media on Marketing, retrieved from: https://www.researchgate.net/publication/300050874_Impact_of_Social_Media_on_Marketing

Tanja Koch (2018), The impact of social media on recruitment: Are you LinkedIn?, retrieved from:https://www.researchgate.net/publication/325018956_The_impact_of_social_media_on_re cruitment_Are_you_LinkedIn

Tina P. Singh (2017), The Impact of Social Media on Business Growth and Performance in India, retrieved from:

http://s3.amazonaws.com/arenaattachments/2329377/43839f512f38d032594f26fb03b4ee5b.pdf?1529398740 


\section{International Journal of Social Science and Economic Research}

ISSN: $2455-8834$

Volume:06, Issue:06 "June 2021"

S Chen (2001), Assessing the impact of the Internet on brands, retrieved from: https://link.springer.com/article/10.1057/palgrave.bm.2540029

Pekka Aula (2010), Social media, reputation risk and ambient publicity management, retrieved from:https://www.researchgate.net/publication/262830769_Social_media_reputation_risk_and_a mbient_publicity_management

Michael L. Kasavana (2010), Online social networking: Redefining the human web, retrieved from:https://www.researchgate.net/publication/235311340_Online_social_networking_Redefinin g_the human_web

Mohammad Yousef Abuhashesh (2014), integration of Social Media in Businesses, retrieved from:https://www.researchgate.net/publication/332466527_Integration_of_Social_Media_in_Bu $\underline{\text { sinesses }}$

Vilma Todri (2014), Social Media Analytics: The Effectiveness of Promotional Events on Brand User Base in Social Media , retrieved from: https://citeseerx.ist.psu.edu/viewdoc/download?doi=10.1.1.726.7002\&rep=rep1\&type=pdf

Laura Mathews (2010) Social Media and the Evolution of Corporate Communications, retrieved from: https://citeseerx.ist.psu.edu/viewdoc/download?doi=10.1.1.622.7845\&rep=rep1\&type=pdf

Ester S. Gonzalez (2013), The impact of internal social media usage on organizational socialization and commitment, retrieved https://www.researchgate.net/publication/287512158_The_impact_of_internal_social_media_usa ge_on_organizational_socialization_and_commitment

W. Glynn Mangold (2009), Social media: The new hybrid element of the promotion mix, retrieved from: https://www.researchgate.net/publication/222415599_Social_media_The_new_hybrid_element of the promotion_mix

Mehdi Abzari (2014), https://rb.gy/pfyzi9

Andrew T. Stephen (2012), The Effects of Traditional and Social Earned Media on Sales: A Study of a Micro Lending Marketplace, retrieved from:

https://www.researchgate.net/publication/228139196_The_Effects_of_Traditional_and_Social_E arned_Media_on_Sales_A_Study_of_a_Microlending_Marketplace

Muhammad Rashid (2018), The Effect of Use of Social Media on Employee Job Performance, retrieved

from: 
International Journal of Social Science and Economic Research

ISSN: 2455-8834

Volume:06, Issue:06 "June 2021"

https://www.researchgate.net/publication/330144196_The_Effect_of_Use_of_Social_Media_on_ Employee_Job_Performance

Rana Muhammad Sohail Jafar (2019), Social media usage and employee's job performance: The moderating role of social media rules, retrieved from: https://www.researchgate.net/publication/336259823_Social_media_usage_and_employee's_job _performance_The_moderating_role_of_social_media_rules

Dr A Arun Kumar (2015), Knowledge Management: A Review, retrieved from: https://www.researchgate.net/publication/280490126_KNOWLEDGE_MANAGEMENT_A_RE $\underline{\text { VIEW }}$

Jordi Paniagua (2020), The interaction between social media, knowledge management and service quality: A decision tree analysis, retrieved from: https://www.ncbi.nlm.nih.gov/pmc/articles/PMC7398501/\#pone.0236735.ref059

Olga Buss (2015), The Impact of Social Media as a Customer Relationship Management Tool, retrieved from:https://www.diva-portal.org/smash/get/diva2\%3A821090/FULLTEXT01.pdf

Peter Cardon (2014), The Hype and Reality of Social Media Use for Work Collaboration and Team Communication, retrieved from: https://rb.gy/z5vjes

Rubathee Nadarja (2013), Social Media Marketing SOCIAL MEDIA MARKETING: ADVANTAGES AND DISADVANTAGES, retrieved https://www.researchgate.net/publication/256296291_Social_Media_Marketing_SOCIAL_MED IA_MARKETING_ADVANTAGES_AND_DISADVANTAGES 